\title{
RESCATE ARQUEOLÓGICO EN EL PARQUE NACIONAL MONTE LEÓN (SANTA CRUZ, ARGENTINA)
}

\author{
MARÍA SOLEDAD CARACOTCHE ${ }^{1}$, ISABEL CRUZ ${ }^{2}$, SILVANA ESPINOSA ${ }^{3}$, \\ FLAVIA CARBALLO MARINA ${ }^{2}$ Y JUAN BAUTISTA BELARDI ${ }^{4}$
}

\begin{abstract}
RESUMEN
Con motivo de la creación del Parque Nacional Monte León (Santa Cruz, Argentina) y para mitigar el impacto producido por diversos procesos naturales y antrópicos, se llevó a cabo el Proyecto de Rescate Arqueológico Monte León. Se obtuvo información artefactual, arqueofaunística y cronológica, que aporta nuevas evidencias a la discusión del uso humano del espacio en la costa atlántica austral. Se destaca la utilización de distintos recursos marinos y de rocas disponibles localmente. No obstante, también se registraron variedades de obsidianas que enmarcan a Monte León dentro de un circuito mayor de interacción. Las ocupaciones humanas registradas se habrían sucedido desde el Holoceno medio y muestran un fuerte componente tardío (últimos 2000 años AP).
\end{abstract}

PALABRAS CLAVES: Holoceno medio y tardío, costa atlántica, rescate arqueológico, cazadores recolectores.

\section{ARCHAEOLOGICAL RECOVERY IN MONTE LEÓN NATIONAL PARK (SANTA CRUZ, ARGENTINA)}

\footnotetext{
ABSTRACT

The Monte León Archaeological Rescue Project resulted from the creation of Monte León National Park (Santa Cruz, Argentina) as a way to mitigate the impact caused by a variety of natural and anthropic processes. The artefact, zooarchaeological, and chronological information developed has offered new evidence for the discussion of past human use of space in the southern Atlantic coast. Noteworthy among these are the use of different marine resources and locally-available rocks. Notwithstanding, finds of various types of obsidian place Monte León within a broader circuit of interaction. Human occupations would have taken place successively since the Mid Holocene, showing a marked increase during the late component (the last 2000 years BP).

KEY WORDS: Middle and Late Holocene, Atlantic coast, archaeological rescue, hunter-gatherers.

1 Delegación Regional Patagonia, Administración de Parques Nacionales. Vicealmirante O'Connor 1188 (8400) S.C. de Bariloche, Río Negro, Argentina. E-mail: scaracotche@apn.gov.ar

2 Unidad Académica Río Gallegos, Universidad Nacional de la Patagonia Austral. Lisandro de la Torre 1070 (9400) Río Gallegos, Santa Cruz, Argentina.

3 CONICET - Unidad Académica Río Gallegos, Universidad Nacional de la Patagonia Austral.

4 Unidad Académica Río Gallegos, Universidad Nacional de la Patagonia Austral - CONICET. Río Gallegos, Santa Cruz, Argentina.
} 


\section{INTRODUCCIÓN}

La reciente creación del Parque Nacional Monte León, en la costa de la provincia de Santa Cruz, y la elaboración del Plan de Manejo para la gestión del área motivaron la realización de un intenso relevamiento arqueológico dentro de los límites del Parque. En este marco, se detectaron más de 26 concentraciones de restos arqueológicos en diversas localizaciones y se registraron varios procesos activos de alta intensidad, que afectaban directamente la conservación de gran parte de los mismos (Caracotche 2003). La erosión, derivada fundamentalmente de la desertificación de la costa patagónica durante los últimos 40 años (Del Valle et al. 1998), y una larga historia de factores antrópicos como la ganadería extensiva, la apertura de rutas y caminos, el uso público y las actividades extractivas y de cateos, llevadas a cabo durante el siglo XX, agravaron considerablemente el efecto de los procesos naturales y pusieron en severo riesgo la integridad del registro arqueológico costero del Parque (Administración de Parques Nacionales 2002).
El potencial arqueológico del área de Monte León ya había sido señalado por Gradín (1961-63), quien efectuó prospecciones durante la década del '60, reconociendo varias concentraciones de materiales arqueológicos, ubicadas en diversos sectores de la costa y caracterizadas por poseer abundantes artefactos líticos y restos de fauna marina y terrestre. Aunque no se efectuaron fechados, la comparación de estos artefactos con los pertenecientes a otros depósitos patagónicos que habían sido datados permitió a Gradín y otros investigadores asignarles una edad correspondiente al Holoceno tardío (ver Caracotche 2003). La riqueza arqueológica de la zona fue confirmada por Caracotche (2003) y por Castro y colaboradores (2004). A partir del diagnóstico acerca del estado de conservación del registro, se puso en marcha el Proyecto Rescate Arqueológico en varias áreas del sector costero del Parque que contaban con concentraciones ubicadas sobre áreas de acampe; depósitos segmentados por la construcción de caminos o que poseían signos claros de erosión retrocedente (Administración de Parques Nacionales

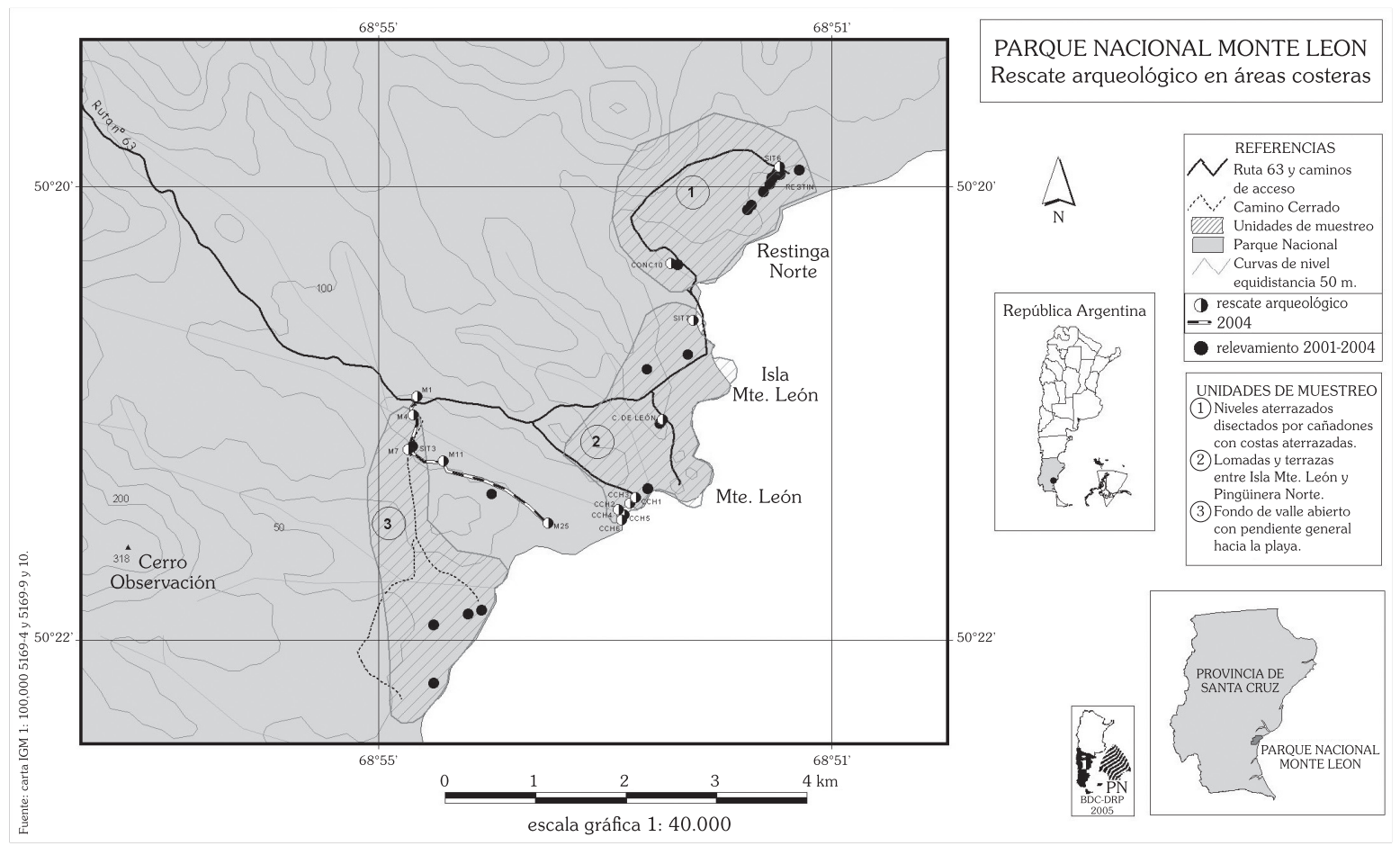

Fig. 1. Mapa de ubicación del Parque Nacional Monte León y los sectores relevados por el Proyecto Rescate Arqueológico Monte León. 
2002) (ver Fig. 1). Este trabajo tiene como objetivo presentar los resultados derivados de este Proyecto, los cuales incluyen el relevamiento de información en el campo y el análisis en laboratorio de los materiales. En primer lugar, se caracterizarán los depósitos arqueológicos relevados en las áreas que abarcó el rescate. Luego, se presentará el marco cronológico obtenido y se discutirán los resultados derivados del análisis de los materiales recuperados integrándolos con otras investigaciones de la costa patagónica continental.

\section{METODOLOGÍA GENERAL}

Como resultado del trabajo de zonificación previa, que determinó los lugares con mayor sensibilidad arqueológica en función de la vulnerabilidad frente a los procesos naturales y antrópicos (ver Caracotche 2003), se implementó una estrategia de rescate. Todos los sectores fueron ubicados mediante GPS y mapeados para su posterior monitoreo respetando la nomenclatura propuesta por la Administración de Parques Nacionales (Administración de Parques Nacionales 2002) (ver Fig. 1).

Se realizaron sondeos en aquellos sectores que presentaban potencial para efectuar excavaciones y eran particularmente vulnerables. En donde la frecuencia de material en superficie era muy alta, se optó por recolectarlos mediante cuadrículas y transectas. Una característica común a todos los lugares en los que se efectuaron relevamientos es que, debido a los procesos de deterioro previamente mencionados, la cubierta vegetal es escasa o nula, por lo cual, la visibilidad fue categorizada como muy buena (>75\%).

La importancia de establecer un marco cronológico para el área y el riesgo de alteración o desaparición de los depósitos determinó la recuperación de distintas muestras (valvas, carbones y huesos) para efectuar fechados radiocarbónicos.

La tecnología lítica se analizó según los lineamientos propuestos por Aschero (1975 rev. 1983), describiéndose atributos diagnósticos de la composición técnica y tipológica de los conjuntos, como el estado de la muestra (presencia de fracturas y estado de conservación), materias primas presentes, variedades de tipos artefactuales, características de la formatización de los instrumentos (unifaciales-bifaciales, presencia de corteza). Se apuntó al reconocimiento de la diversidad de los conjuntos líticos, la que supone la cantidad de tipos de artefactos por clase funcional y por materia prima, y de las propiedades características de los mismos. Cabe destacar que en el análisis y en los cómputos de las frecuencias artefactuales se consideraron los desechos con talón. Esta información se presenta discriminada según los sitios trabajados y estableciendo la relación entre artefactos formatizados y desechos y entre desechos corticales e internos.

Con respecto a la arqueofauna, sólo se recuperaron restos en dos de los sectores trabajados. Debido a que en uno de ellos sólo se registraron cuatro especímenes óseos, el análisis se centró en los restos del conchero $\mathrm{CCH} 4$. Se efectuó la determinación taxonómica en el nivel de especie, género o familia en todos aquellos casos en los que fue posible. En los que no lo fue, los especímenes fueron incluidos en categorías taxonómicas más amplias, como ave, mamífero o pinnípedo. Se relevaron las siguientes modificaciones óseas: estadios de meteorización, fracturas, daños de carnívoros, marcas de raíces, modificaciones por agua, marcas de pisoteo, modificaciones culturales y marcas superficiales indeterminadas. Para evaluar la meteorización en los huesos de mamíferos de más de $5 \mathrm{~kg}$ de peso, se utilizaron los estadios propuestos por Behrensmeyer (1978). En el caso de los huesos de aves, se utilizaron los propuestos para aves de la costa de Tierra del Fuego (Muñoz y Savanti 1998). Los criterios morfológicos para definir los daños de carnívoros son los determinados por Binford (1981) y los correspondientes a daños por roedores y a daños por raíces según Lyman (1994). Se considera que un espécimen óseo ha sido modificado por el agua cuando se observan cambios leves en la coloración y en la consistencia del hueso, así como un leve redondeamiento de las aristas (Cruz 2003).

\section{RESULTADOS OBTENIDOS POR SECTOR}

\section{A) Sector Pingüinera Norte}

Todo el sector se encuentra surcado por cañadones, cuya dinámica, en la que la erosión retrocedente es predominante, afecta al registro arqueológico, trasladando, redepositando y expo- 


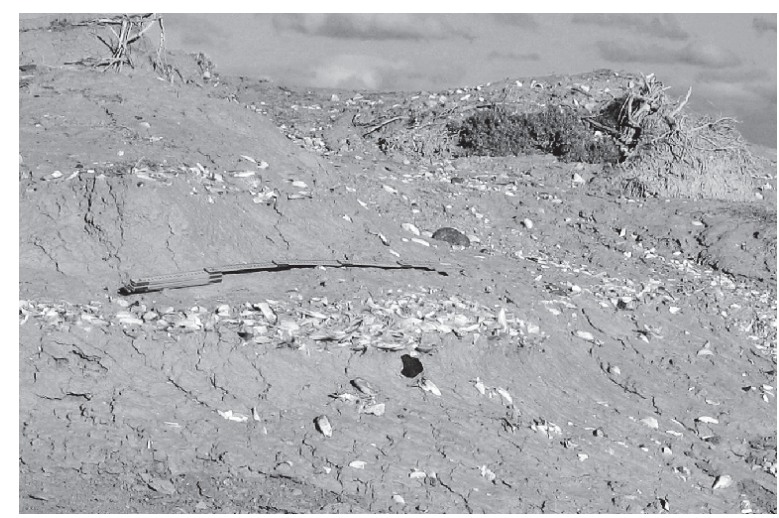

Fig. 2. Vista general del conchero $\mathrm{CCH} 1$.

niendo diferentes tipos de materiales (Caracotche 2003). Los depósitos arqueológicos se presentan mayoritariamente como concheros. Tres de ellos están ubicados en el área de nidificación actual de pingüinos de Magallanes (Spheniscus magellanicus), por lo que se evaluó que la acción de los pingüinos podía afectar los depósitos (ver Cruz 2001, 2004).

A continuación, se mencionan las tareas y observaciones llevadas a cabo en seis concheros del sector.

Conchero 1. Se registraron dos niveles de conchero y se procedió a tomar muestras de valvas para datación radiocarbónica de cada uno de ellos. Se recuperaron las siguientes especies de moluscos: Acantina sp., Patinigera sp., Mytilus chilensis.

Conchero 2. Se ubica sobre un cañadón abierto por erosión retrocedente, a $90 \mathrm{~cm}$ de la superficie actual. Tiene exposición Este y presenta una potencia de unos $10-18 \mathrm{~cm}$. Sobre el perfil se observó también una lente carbonosa, así como valvas (Aulacomya ater y Mytilus chilensis), conchillas (Trophon sp. y Acantina sp.) y escaso material lítico y arqueofaunístico.

Conchero 3. La lente expuesta sobre el perfil presenta unos $10 \mathrm{~cm}$ de potencia. Las valvas que formaron parte del conchero se deslizan actualmente por el talud y se encuentran asociadas a huesos actuales de pingüinos de Magallanes, así como a artefactos líticos y restos arqueofaunísticos. Se tomaron muestras de valvas (Patinigera sp., Aulacomya ater, Mytilus chilensis) para su datación.

Conchero 4. Su extensión mayor es de 20,4 m. Su importante potencia determinó la excavación de una cuadrícula de 80 x $50 \mathrm{~cm}$, en la que se siguieron niveles artificiales de $5 \mathrm{~cm}$, llegándose a una profundidad de $129 \mathrm{~cm}$. En los casos en que se detectaron cambios naturales en el sedimento o los restos incluidos en ellos, se consideraron nuevos niveles. Es decir que en el total de 17 niveles de excavación, se alternan estratos naturales y artificiales. La matriz de este conchero es arcillo-arenosa y presenta diferentes grados de coloración y compactación a lo largo de la estratigrafía. Se observaron distintas lentes de carbón asociadas a artefactos líticos, como es el caso del Nivel 7. Se recuperaron, además, diversos restos arqueofaunísticos, entre los que se incluyen huesos de guanaco (Lama guanicoe), cormorán (Phalacrocorax sp.) y Pinnípedos, así como valvas y conchillas de varios moluscos, como Patinigera magellanica, Mytilus chilensis, Aulacomya ater, Trophon sp. y Acantina sp. Se recolectaron también los materiales líticos y arqueofaunísticos expuestos en la superficie y sobre los perfiles asociados. Además, la alta frecuencia artefactual expuesta en la barranca en sectores asociados a este conchero llevó a plantear cuatro unidades de recolección, ubicadas cada 5 metros orientadas en dirección O- E.

En este sector los procesos de deterioro son muy rápidos; por ejemplo, este cañadón se inunda por mareas extraordinarias, acelerando la erosión del pie de la barranca. Este proceso fue observado durante los trabajos de campo y es posible que sea uno de los factores que provocaron el derrumbe del perfil, ya alterado por pequeñas cárcavas que drenan hacia el cañadón. Por otra parte, la presencia de nidos activos de pingüino de Magallanes alrededor de este conchero constituye otro factor de potencial riesgo para los depósitos, debido a que estos nidos se excavaron en sustrato que contiene restos arqueológicos. El sitio es analizado en detalle más adelante.

Conchero 5. Corresponde a uno de los dos niveles de conchero registrado sin material arqueológico asociado; que fueron denominados A y B. Se procedió a tomar una muestra de valvas en cada uno de ellos para su datación radiocarbónica.

Conchero 6. La lente de este conchero se está descubriendo y tiene una potencia de entre 15 y $20 \mathrm{~cm}$, se tomó una muestra de valvas para fechar y se recuperó un fragmento de hueso largo de ñandú en superficie. 
B) Zona de Uso Público:

Área de Acampe (CONC10)

Se detectó una importante concentración de artefactos líticos en sectores utilizados como parcelas de acampe, que evidencian otros signos de uso público intensivo (como pisoteo y apertura de caminos internos). Se realizaron transectas que cubrieron un sector de $84 \mathrm{~m}$ en dirección N-S y 37 $\mathrm{m}$ en sentido E-O. A lo largo de toda la superficie se observaron valvas dispersas.

Se observaron cuevas activas de Dacipódidos, las que constituyen otro factor de perturbación de los depósitos arqueológicos, ya que se observaron artefactos asociados a las cuevas mencionadas. En función de estas observaciones, se efectuó un sondeo de $50 \mathrm{~cm}$ de lado, el que presentó material arqueológico en los primeros 5-10 cm de sedimento eólico. Bajo este nivel, se detectó un estrato de arena consolidada que no contenía restos. El sitio se analiza en detalle más adelante.

\section{C) Zona de Uso Público: Restinga Norte (SIT6)}

Este sitio fue impactado por la apertura de la actual Ruta 63, que expuso material arqueológico a lo largo de aproximadamente $16 \mathrm{~m}$ a ambos lados del camino. En un resalto del mismo se ubicó, sobre un perfil, una lente carbonosa de aproximadamente $1,5 \mathrm{~m}$ de longitud, contenida en un sedimento eólico de unos 10-15 cm de espesor. En otros sectores del perfil, los materiales arqueológicos se encuentran a unos $20 \mathrm{~cm}$ de la superficie actual, lo que indicaría que, en el sector de la lente de carbón, parte del sedimento se ha erosionado. Se planteó un sondeo de 80 × $30 \mathrm{~cm}$ para exponer el nivel de carbones que presenta una potencia de entre 7 y $10 \mathrm{~cm}$. Por debajo del mismo se registró un estrato de arena consolidada con valvas. Se registraron una lasca primaria entera de dacita, dos fragmentos indiferenciados de dacita, dos fragmentos indiferenciados de basalto y una lasca angular sin talón de dacita.

Se recolectaron los materiales líticos en superficie a lo largo de $23 \mathrm{~m}$ sobre el camino. Para ello, se plantearon tres cuadrículas, dos de las cuales se emplazaron sobre el camino, cubriendo respectivamente $2 \mathrm{~m}^{2}$ y $1 \mathrm{~m}^{2}$. La tercera cuadrícula $\left(1 \mathrm{~m}^{2}\right)$ se emplazó sobre el caballete sur del camino. Entre los artefactos recuperados se destaca el hallazgo de una lasca de obsidiana negra. Por otro lado, se detectó la presencia de materiales arqueológicos asociados a un bosquete de molles (Schinus polygamus) aledaño al camino, el que fue desmontado por la traza del mismo.

D) Camino de acceso a Zona de Uso Público (SIT7)

Está ubicado sobre una lomada y presenta una extensión de más de $100 \mathrm{~m}$ de largo. Sufrió severos impactos por las tareas de repaso y mantenimiento de la Ruta 63, que lo dividió en dos exponiendo perfiles y materiales arqueológicos (2003). A 10 $\mathrm{m}$ al Este de la Ruta se plantearon dos cuadrículas de recolección, la primera cubrió una superficie de $1 \mathrm{~m}^{2}$ en un sector de pavimento de erosión. La segunda, ubicada sobre un drenaje desactivado, abarcó una superficie de $3 \mathrm{~m}^{2}$. Se identificaron rodados probados de calidad regular, con una o dos extracciones, así como lascas primarias de grandes dimensiones. En todo el sector, los artefactos se encontraban muy dispersos como consecuencia de los arrastres y la redepositación derivados de la acción eólica e hídrica. En el sector entre la Ruta y la línea de costa actual, se observó que el material arqueológico se hallaba contenido en una matriz eólica de entre $5-15 \mathrm{~cm}$, la que presentaba valvas, huesos de Pinnípedos y de guanaco, así como una pequeña lente carbonosa. Luego el sitio es presentado en detalle.

\section{E) Camino de acceso a Cabeza de León (C de León)}

La concentración de restos arqueológicos detectada en este sector es una de las más extensas y densas de toda el área y ha sido objeto de depredación por coleccionistas y aficionados. Las mayores frecuencias artefactuales se registraron a lo largo de $187 \mathrm{~m}$ en el sector medio del camino de acceso a Cabeza de León. Hacia el sur, la distribución alcanza $142 \mathrm{~m}$ y hacia el norte se extiende por 70 $\mathrm{m}$. Hacia el sur del camino, se encuentra un grupo de molles asociado a una gran concentración de artefactos líticos en un sector que abarca un largo total de $104 \mathrm{~m}$ en sentido E-O y $60 \mathrm{~m}$ en sentido N-S. Allí se recolectaron los artefactos a partir de dos cuadrículas de $2 \mathrm{~m}^{2}$ cada una. Los materiales 
Tabla 1. Fechados radiocarbónicos en el P. N. Monte León (Santa Cruz, Argentina).

\begin{tabular}{|c|c|c|c|c|c|}
\hline Sitio & $\begin{array}{l}\text { Tipo de } \\
\text { muestra }\end{array}$ & $\begin{array}{c}\text { Sigla } \\
\text { Laboratorio }\end{array}$ & $\begin{array}{c}\text { Edad C-14 } \\
\text { Convencional }\end{array}$ & $\begin{array}{c}\text { Edad corregida por } \\
\text { efecto reservorio marino }\end{array}$ & $\begin{array}{c}\text { Edad Calibrada ( } \pm 2 \\
\text { sigmas)* }\end{array}$ \\
\hline $\begin{array}{c}\text { CCH } 1 \\
\text { Nivel inferior }\end{array}$ & valvas & LP 1539 & $5550 \pm 90 \mathrm{AP}$ & $5150 \pm 90$ AP & 5720-6163 cal AP \\
\hline $\mathrm{CCH} 2$ & valvas & LP 1523 & $1560 \pm 70 \mathrm{AP}$ & $1160 \pm 70 \mathrm{AP}$ & $942-1256 \mathrm{cal} \mathrm{AP}$ \\
\hline $\begin{array}{c}\text { CCH } 3 \\
\text { Muestra } 1 \\
\end{array}$ & carbón & LP 1545 & $4160 \pm 80 \mathrm{AP}$ & - & $4435-4864 \mathrm{cal}$ AP \\
\hline $\begin{array}{c}\text { CCH } 4 \\
\text { Nivel } 40-48 \mathrm{~cm} \\
\end{array}$ & valvas & LP 1515 & $1330 \pm 60 \mathrm{AP}$ & $930 \pm 60$ AP & 727-970 cal AP \\
\hline $\begin{array}{c}\text { CCH } 4 \\
\text { Nivel } 65 \mathrm{~cm} \\
\end{array}$ & carbón & LP 1583 & $1380 \pm 50 \mathrm{AP}$ & - & 1185-1351 cal AP \\
\hline $\begin{array}{c}\text { CCH } 4 \\
\text { Nivel } 85-93 \mathrm{~cm} \\
\end{array}$ & valvas & LP 1565 & $1830 \pm 70 \mathrm{AP}$ & $1430 \pm 70$ AP & $1245-1515 \mathrm{cal}$ AP \\
\hline $\begin{array}{c}\text { CCH } 4 \\
\text { Nivel } 85-93 \mathrm{~cm} \\
\end{array}$ & carbón & LP 1609 & $1320 \pm 60 \mathrm{~A}$ & - & $1088-1330 \mathrm{cal} \mathrm{AP}$ \\
\hline $\begin{array}{c}\text { CCH } 4 \\
\text { Nivel } 112-117 \mathrm{~cm} \\
\end{array}$ & valvas & LP 1555 & $1700 \pm 60 \mathrm{AP}$ & $1300 \pm 60$ AP & 1127-1339 cal AP \\
\hline SIT 6 & carbón & LP 1526 & $650 \pm 75$ AP & - & 519-701 cal AP \\
\hline
\end{tabular}

*Calibración realizada por el laboratorio.

recuperados son presentados más adelante. Por otra parte, se observaron abundantes valvas dispersas y fragmentadas, que posiblemente sean restos de concheros.

F) Sendero Pingüinera Sur (SPS)

En el Sendero de acceso al mirador de la Pingüinera Sur, se decidió efectuar la recolección de los artefactos por medio de una transecta lineal continua, planteada sobre el eje del camino. Se consideraron unidades de muestreo de $100 \mathrm{~m}$ de largo por $3 \mathrm{~m}$ de ancho, 22 de las cuales contienen materiales arqueológicos en frecuencias variables. Las más altas se registraron al inicio de la transecta (muestreos 1 y 2), en el muestreo 6 - que atraviesa una laguna seca, en cuya margen sur se efectuó la recolección de una importante concentración de artefactos - y en los muestreos finales (21-25). Los artefactos recuperados son presentados más adelante.

\section{MARCO CRONOLÓGICO}

A continuación (Tabla 1) se presentan los resultados cronológicos obtenidos en los distintos sitios trabajados (ver Fig. 1).

El fechado correspondiente al Nivel inferior de CCH 1 es uno de los más tempranos obtenidos hasta el momento en el sur de la costa de Patagonia continental. En esta región, la fecha más temprana,
$6060 \pm 70$ años AP, es la registrada en el sitio Cabo Tres Puntas, en el norte de Santa Cruz (Castro y Moreno 1996-98). Los fechados más tardíos de Monte León son acordes a los registrados en otros sectores de la costa sur del continente. Este es el caso de los sitios de Cabo Vírgenes (Borrero y Franco 1999; Franco et al. 2004; L'Heureux y Franco 2002), del estuario del río Gallegos (Mansur et al. 2004) y otros en la costa norte de Santa Cruz (Castro et al. 2003).

\section{MATERIALES LÍTICOS}

Seguidamente se presenta la información relevada en cada uno de los sitios estudiados. Los índices de fractura señalan el buen estado de las muestras, ya que a excepción de los niveles estratigráficos de $\mathrm{CCH} 4$, las piezas que conservan el talón alcanzan porcentajes superiores al 65\% (por ejemplo, CCH 4 -superficie- con el 84,6\%, CONC 10 con el 89,86\%, SIT 6 con el 65\%, C de León con el 91\% y SPS con el 83\%. Esto garantiza el registro de la mayor variedad de atributos, a fin de establecer tendencias generales. Se destaca el predominio de las rocas de muy buena calidad para la talla.

\section{CONCHERO 4 (CCH 4)}

En primer término, se presenta la información proveniente de superficie $y$, seguidamente, los datos 
Tabla 2. $\mathrm{CCH} 4$, Frecuencias y porcentajes de clases artefactuales por materia prima.

\begin{tabular}{|c|c|c|c|c|c|c|}
\cline { 2 - 6 } \multicolumn{1}{c|}{} & \multicolumn{9}{c|}{ MATERIA PRIMA } & Riolita & TOTAL y $\%$ \\
\hline CLASE ARTEFACTUAL & Dacita & Basalto & Arenisca & 0 & 0 & $3(5,17 \%)$ \\
\hline Núcleo & 2 & 1 & 0 & 0 & 0 & $1(1,72 \%)$ \\
\hline Piece esquillé & 0 & 1 & 0 & 0 & 1 & $6(10,34 \%)$ \\
\hline Raedera & 3 & 2 & 0 & 2 & 0 & $27(46,55 \%)$ \\
\hline Lasca angular & 11 & 13 & 1 & 0 & 1 & $9(15,51 \%)$ \\
\hline Lasca arista & 7 & 1 & 0 & 0 & 0 & $1(1,72 \%)$ \\
\hline Lasca de reactivación & 1 & 0 & 0 & 0 & 0 & $2(3,44 \%)$ \\
\hline directa & 2 & 0 & 0 & 0 & 0 & $2(3,44 \%)$ \\
\hline Lasca de dorso natural & 1 & 1 & 0 & 1 & 0 & $2(3,44 \%)$ \\
\hline Lasca plana & 0 & 1 & 0 & 0 & 1 & $5(8,62 \%)$ \\
\hline Lasca primaria & 3 & 1 & 0 & $3(5,17 \%)$ & $3(5,17 \%)$ & 5 \\
\hline TOTAL y $\%$ & $30(51,72 \%)$ & $21(36,20 \%)$ & $1(1,72 \%)$ & 58 & 0 \\
\hline
\end{tabular}

estratigráficos. Como puede observarse en la Tabla 2 , este conjunto no presenta una amplia variedad de artefactos formatizados $(n=5)$ ni de materias primas, siendo la dacita la de mayor variedad de tipos y con presencia de corteza. Se destacan las raederas y las lascas angulares. Estas últimas refuerzan la tendencia general de altos porcentajes de lascas internas.

Las Tablas 3 y 4 indican el desarrollo de las primeras etapas en la manufactura de artefactos, principalmente en dacita y basalto.

La baja frecuencia de hallazgos en estratigrafía no permite establecer tendencias generales. A continuación se presentan los materiales recuperados. En el NIVEL 1 (40-48 cm) se registró una lasca angular entera de dacita. En el NIVEL 2 (48-50 $\mathrm{cm}$ ) se rescataron cuatro desechos de talla (tres de dacita y uno de basalto), tres de ellos conservan el talón. Se trata de dos lascas angulares enteras, una de basalto y otra de dacita. La restante es una lasca de dorso natural en dacita. En el NIVEL 3 (50-55 $\mathrm{cm}$ ), el total de desechos de talla es cuatro (dos de basalto y dos de dacita). Sólo dos conservan el talón; se trata de dos lascas angulares (una de basalto y otra de dacita). El NIVEL $4(55-60 \mathrm{~cm})$ presenta 13 desechos de talla (dos de basalto, ocho de dacita, uno de ópalo, uno de diabasa y uno de arenisca), siete conservan el talón, mayoritariamente en dacita. El NIVEL $5(60-63,5 \mathrm{~cm})$ consta de ocho desechos de talla (siete de dacita y uno de lutita) y un percutor fracturado en dacita. Cinco desechos conservan su talón. El NIVEL $8(73,5-78,5 \mathrm{~cm})$ presenta cuatro desechos de talla de dacita, solamente dos enteros. El NIVEL $9(78,5-83,5 \mathrm{~cm})$ está integrado por dos desechos de talla de dacita que conservan el talón. Finalmente, el NIVEL $11(88,5-93,5 \mathrm{~cm})$ consta de un total de cinco desechos de talla (cuatro de dacita y uno de arenisca), tres de los cuales conservan el talón.

\section{ÁREA DE ACAMPE (CONC10)}

Es uno de los sitios de mayor frecuencia artefactual $(n=625)$ y variedad de clases. Se registraron

Tabla 3. $\mathrm{CCH}$ 4, Porcentajes de artefactos formatizados y desechos de talla por materia prima.

\begin{tabular}{|c|c|c|c|c|c|}
\cline { 2 - 6 } \multicolumn{1}{c|}{} & \multicolumn{5}{c|}{ MATERIA PRIMA } \\
\cline { 2 - 6 } \multicolumn{1}{c|}{} & Dacita & Basalto & Arenisca & Sílice & Riolita \\
\hline Artefactos formatizados & 16,6 & 19,04 & 0 & 0 & 33,3 \\
\hline Desechos de talla & 83,3 & 80,95 & 100 & 100 & 66,6 \\
\hline
\end{tabular}

Tabla 4. CCH 4, Porcentajes de desechos de talla corticales e internos por materia prima.

\begin{tabular}{|c|c|c|c|c|c|}
\cline { 2 - 6 } \multicolumn{1}{c|}{} & \multicolumn{5}{c|}{ MATERIA PRIMA } \\
\cline { 2 - 6 } \multicolumn{1}{c|}{} & Dacita & Basalto & Arenisca & Sílice & Riolita \\
\hline Desechos de talla corticales & 9,09 & 11,76 & 0 & 33,33 & 50 \\
\hline Desechos de talla internos & 90,9 & 88,23 & 100 & 66,66 & 50 \\
\hline
\end{tabular}


54 artefactos formatizados y 514 desechos de talla. Predominan los núcleos y las puntas de proyectil, mientras que entre los desechos de talla se destacan las lascas angulares y, en menores frecuencias, las lascas primarias y secundarias (Tabla 5). La Tabla 5 también indica que la roca más utilizada ha sido la dacita y que la presencia de corteza es mayoritaria en basalto y dacita y en menor proporción en calcedonia.

Las relaciones entre artefactos formatizados/ desechos de talla (Tabla 6) y desechos corticales/ desechos internos (Tabla 7) refleja el desarrollo de actividades de manufactura más claramente que en $\mathrm{CCH} 4$, principalmente tareas de descortezamiento en una amplia variedad de rocas. Se destaca la presencia de obsidianas verde y gris verdosa veteada. En relevamientos previos en el sector, Caracotche (2003) registró el limbo de una punta de proyectil confeccionada en obsidiana verde. Por otra parte, la amplia variedad de clases artefactuales evidenciaría un uso diversificado de este espacio y/o reiterado en el tiempo.

Tabla 5. CONC 10, Frecuencias de clases artefactuales por materia prima.

\begin{tabular}{|c|c|c|c|c|c|c|c|c|c|c|c|c|c|}
\hline & \multicolumn{12}{|c|}{ MATERIA PRIMA } & \multirow[b]{2}{*}{ TOTAL y $\%$} \\
\hline \begin{tabular}{|c|} 
CLASE \\
ARTEFACTUAL
\end{tabular} & Dac & Bas & Cal & Are & Rio & Ande & O. gvv & Gra & Op & Dia & O. v & Limo & \\
\hline AFS & 2 & 0 & 1 & 0 & 0 & 0 & 0 & 0 & 0 & 0 & 0 & 0 & $3(0,52 \%)$ \\
\hline Biface & 2 & 1 & 2 & 0 & 0 & 0 & 0 & 0 & 0 & 0 & 0 & 0 & $5(0,88 \%)$ \\
\hline Cepillo & 1 & 0 & 0 & 0 & 0 & 0 & 0 & 0 & 0 & 0 & 0 & 0 & $1(0,17 \%)$ \\
\hline Cuchillo & 2 & 1 & 0 & 1 & 0 & 0 & 0 & 0 & 0 & 0 & 0 & 0 & $4(0,70 \%)$ \\
\hline FAF & 1 & 1 & 0 & 0 & 1 & 0 & 0 & 0 & 0 & 0 & 0 & 0 & $3(0,52 \%)$ \\
\hline $\begin{array}{l}\text { Filo natural } \\
\text { con rastros }\end{array}$ & 3 & 1 & 0 & 0 & 0 & 1 & 0 & 0 & 0 & 0 & 0 & 0 & $5(0,88 \%)$ \\
\hline $\begin{array}{l}\text { Guijarro } \\
\text { probado }\end{array}$ & 3 & 1 & 0 & 0 & 0 & 0 & 0 & 0 & 0 & 0 & 0 & 0 & $4(0,70 \%)$ \\
\hline Núcleo & 5 & 4 & 0 & 2 & 0 & 0 & 0 & 0 & 0 & 0 & 0 & 0 & $11(1,93 \%)$ \\
\hline $\begin{array}{l}\text { Punta de } \\
\text { proyectil }\end{array}$ & 2 & 3 & 2 & 0 & 0 & 0 & 0 & 0 & 0 & 0 & 1 & 0 & $8(1,40 \%)$ \\
\hline Percutor & 0 & 0 & 0 & 0 & 0 & 0 & 0 & 1 & 0 & 0 & 0 & 0 & $1(0,17 \%)$ \\
\hline Raedera & 4 & 0 & 0 & 0 & 1 & 0 & 0 & 0 & 0 & 0 & 0 & 0 & $5(0,88 \%)$ \\
\hline Raspador & 1 & 0 & 1 & 0 & 0 & 0 & 0 & 0 & 2 & 0 & 0 & 0 & $4(0,70 \%)$ \\
\hline Lasca angular & 185 & 68 & 8 & 7 & 3 & 2 & 0 & 2 & 0 & 2 & 1 & 1 & $279(49,11 \%)$ \\
\hline \begin{tabular}{|c|} 
Lasca de dorso \\
natural
\end{tabular} & 20 & 16 & 0 & 0 & 0 & 0 & 0 & 1 & 0 & 1 & 0 & 1 & $39(6,86 \%)$ \\
\hline $\begin{array}{c}\text { Lasca de } \\
\text { adelgazamiento } \\
\text { bifacial }\end{array}$ & 22 & 8 & 3 & 1 & 2 & 0 & 0 & 0 & 0 & 0 & 0 & 0 & $36(6,33 \%)$ \\
\hline Lasca de arista & 10 & 2 & 1 & 1 & 0 & 0 & 0 & 0 & 0 & 0 & 1 & 1 & $16(2,81 \%)$ \\
\hline $\begin{array}{c}\text { Lasca de flanco } \\
\text { de núcleo }\end{array}$ & 2 & 0 & 0 & 0 & 0 & 0 & 0 & 0 & 0 & 0 & 0 & 0 & $2(0,35 \%)$ \\
\hline $\begin{array}{c}\text { Lasca } \\
\text { indiferenciada }\end{array}$ & 6 & 3 & 0 & 0 & 0 & 0 & 0 & 0 & 0 & 0 & 0 & 0 & $9(1,58 \%)$ \\
\hline Lasca plana & 5 & 2 & 0 & 0 & 0 & 0 & 0 & 0 & 0 & 0 & 0 & 0 & $7(1,23 \%)$ \\
\hline Lasca primaria & 16 & 16 & 1 & 0 & 4 & 0 & 0 & 2 & 0 & 0 & 0 & 0 & $39(6,86 \%)$ \\
\hline \begin{tabular}{|c|} 
Lasca \\
reactivación \\
directa
\end{tabular} & 16 & 4 & 2 & 1 & 1 & 0 & 0 & 0 & 1 & 0 & 0 & 0 & $25(4,40 \%)$ \\
\hline $\begin{array}{c}\text { Lasca } \\
\text { secundaria }\end{array}$ & 33 & 17 & 2 & 3 & 2 & 1 & 1 & 1 & 1 & 0 & 0 & 1 & $62(10,91 \%)$ \\
\hline TOTAL y $\%$ & \begin{tabular}{|c|}
341 \\
$60,03 \%$
\end{tabular} & $\begin{array}{c}148 \\
26,03 \%\end{array}$ & \begin{tabular}{|c|}
23 \\
$4,49 \%$ \\
\end{tabular} & \begin{tabular}{|c|}
16 \\
$2,81 \%$ \\
\end{tabular} & $\begin{array}{c}14 \\
2,46 \%\end{array}$ & \begin{tabular}{|c|}
4 \\
$0,70 \%$
\end{tabular} & \begin{tabular}{|c|}
1 \\
$0,17 \%$ \\
\end{tabular} & \begin{tabular}{|c|}
7 \\
$1,23 \%$ \\
\end{tabular} & $\begin{array}{c}4 \\
0,70 \%\end{array}$ & $\begin{array}{c}3 \\
0,52 \%\end{array}$ & \begin{tabular}{|c|}
3 \\
$0,52 \%$ \\
\end{tabular} & $\begin{array}{c}4 \\
0,70 \%\end{array}$ & 568 \\
\hline
\end{tabular}

Referencias: AFS: artefacto de formatización sumaria, FAF: fragmento de artefacto formatizado, Dac: dacita, Bas: basalto, Cal: calcedonia, Are: arenisca, Rio: riolita, Ande: andesita, O. gvv: Obsidiana gris verdosa veteada, Gra: granito, Op: ópalo, 
Tabla 6. CONC 10, Porcentajes de artefactos formatizados y desechos de talla por materia prima.

\begin{tabular}{|c|c|c|c|c|c|c|c|c|c|c|c|c|}
\hline & \multicolumn{12}{|c|}{ MATERIA PRIMA } \\
\hline & Dac & Bas & Cal & Are & Rio & Gra & O. gvv & Ande & O. v & $\mathrm{Op}$ & Dia & Limo \\
\hline $\begin{array}{c}\text { Artefactos } \\
\text { formatizados }\end{array}$ & 7,89 & 8,1 & 26,08 & 18,7 & 14,2 & 14,2 & 33,33 & 0 & 0 & 0 & 25 & 0 \\
\hline Desechos de talla & 92,1 & 91,8 & 73,9 & 81,2 & 85,7 & 85,7 & 66,66 & 100 & 100 & 100 & 75 & 100 \\
\hline
\end{tabular}

Referencias: Dac: dacita, Bas: basalto, Cal: calcedonia, Are: arenisca, Rio: riolita, Gra: granito, O. gvv: Obsidiana gris verdosa veteada, Ande: andesita, O. v: obsidiana verde, Op: ópalo, Dia: diabasa, Limo: limolita.

Tabla 7. CONC 10, Porcentajes de desechos corticales e internos por materia prima.

\begin{tabular}{|c|c|c|c|c|c|c|c|c|c|c|c|c|c|}
\cline { 2 - 13 } \multicolumn{1}{c|}{} & \multicolumn{10}{c|}{ MaTERIA PRIMA } \\
\cline { 2 - 13 } & Dac & Bas & Cal & Are & Rio & Gra & O. gvv & Ande & O. v & Op & Dia & Limo \\
\hline $\begin{array}{c}\text { Desechos de talla } \\
\text { corticales }\end{array}$ & 21,9 & 36 & 17,6 & 23 & 50 & 66,6 & 100 & 33,3 & 0 & 50 & 33,3 & 50 \\
\hline $\begin{array}{c}\text { Desechos de talla } \\
\text { internos }\end{array}$ & 78 & 63,9 & 82,3 & 76,9 & 50 & 33,3 & 0 & 66,6 & 100 & 50 & 66,6 & 50 \\
\hline
\end{tabular}

Referencias: Dac: dacita, Bas: basalto, Cal: calcedonia, Are: arenisca, Rio: riolita, Gra: granito, O. gvv: Obsidiana gris verdosa veteada, Ande: andesita, O. v: obsidiana verde, Op: ópalo, Dia: diabasa, Limo: limolita.

\section{RESTINGA NORTE SITIO 6 (SIT 6)}

Este sitio presenta una baja frecuencia de hallazgos ( $n=26$, Tabla 8 ) y posee una reducida variedad de tipos artefactuales y de materias primas. Se registraron 5 artefactos formatizados (mayoritariamente raederas) y 12 desechos de talla. Entre ellos, se destacan las lascas angulares seguidas por las lascas con reserva de corteza.

La relación artefactos formatizados/desechos de talla sólo se presenta entre los artefactos manufacturados en dacita y lutita. En sílice se ha registrado un núcleo, sin embargo no hay correlato entre los desechos de talla. A pesar del reducido tamaño de la muestra se mantiene la tendencia general sobre la evidencia de las primeras etapas de la manufactura (Tabla 9).

\section{SITIO 7 (SIT 7)}

Se registraron 5 artefactos formatizados y 49 desechos de talla. Son pocas las clases artefactuales; no obstante, las variedades de materias primas incluyen rocas no presentes en los demás conjuntos,

Tabla 8. SIT 6, Frecuencias de clases artefactuales por materia prima.

\begin{tabular}{|c|c|c|c|c|c|c|c|}
\hline & \multicolumn{6}{|c|}{ MATERIA PRIMA } & \\
\hline CLASE ARTEFACTUAL & Dacita & Basalto & Lutita & Sílice & Riolita & Diabasa & TOTAL y $\%$ \\
\hline Biface & 1 & 0 & 0 & 0 & 0 & 0 & $1(5,88 \%)$ \\
\hline Raedera & 2 & 0 & 1 & 0 & 0 & 0 & $3(17,64 \%)$ \\
\hline Raspador & 1 & 0 & 0 & 0 & 0 & 0 & $1(5,88 \%)$ \\
\hline Núcleo & 1 & 0 & 0 & 1 & 0 & 0 & $2(11,76 \%)$ \\
\hline Lasca angular & 4 & 1 & 0 & 0 & 0 & 0 & $5(29,41 \%)$ \\
\hline Lasca dorso & 1 & 0 & 0 & 0 & 0 & 1 & $2(11,76 \%)$ \\
\hline Lasca de arista & 0 & 0 & 1 & 0 & 1 & 0 & $2(11,76 \%)$ \\
\hline Lasca primaria & 1 & 0 & 0 & 0 & 0 & 0 & $1(5,88 \%)$ \\
\hline TOTAL y $\%$ & $\begin{array}{c}11 \\
(64,70 \%) \\
\end{array}$ & $\begin{array}{c}1 \\
(5,88 \%) \\
\end{array}$ & $\begin{array}{c}2 \\
(11,76 \%)\end{array}$ & $\begin{array}{c}1 \\
(5,88 \%) \\
\end{array}$ & $\begin{array}{c}1 \\
(5,88 \%) \\
\end{array}$ & $\begin{array}{c}1 \\
(5,88 \%) \\
\end{array}$ & 17 \\
\hline
\end{tabular}

Tabla 9. SIT 6, Porcentajes de desechos de talla corticales e internos por materia prima.

\begin{tabular}{|c|c|c|c|c|c|c|}
\cline { 2 - 7 } \multicolumn{1}{c|}{} & \multicolumn{5}{c|}{ MATERIA PRIMA } \\
\cline { 2 - 7 } \multicolumn{1}{c|}{} & Dacita & Basalto & Lutita & Sílice & Riolita & Diabasa \\
\hline Desechos de talla corticales & 33,33 & 0 & 0 & 0 & 0 & 100 \\
\hline Desechos de talla internos & 66,66 & 100 & 100 & 100 & 100 & 0 \\
\hline
\end{tabular}


Tabla 10. SIT 7, Frecuencias de clases artefactuales por materia prima.

\begin{tabular}{|c|c|c|c|c|c|c|}
\hline \multirow[b]{2}{*}{ CLASE ARTEFACTUAL } & \multicolumn{5}{|c|}{ MATERIA PRIMA } & \multirow[b]{2}{*}{ TOTAL y \% } \\
\hline & Dacita & Basalto & Calcedonia & $\begin{array}{c}\text { Obsidiana } \\
\text { negra }\end{array}$ & $\begin{array}{c}\text { Madera } \\
\text { silicificada }\end{array}$ & \\
\hline Biface & 1 & 0 & 0 & 0 & 0 & $1(1,85 \%)$ \\
\hline Núcleo & 0 & 0 & 0 & 1 & 0 & $1(1,85 \%)$ \\
\hline Raedera & 1 & 0 & 0 & 0 & 0 & $1(1,85 \%)$ \\
\hline Raspador & 1 & 0 & 0 & 0 & 1 & $2(3,70 \%)$ \\
\hline Lasca adelgazamiento bifacial & 1 & 0 & 0 & 0 & 0 & $1(1,85 \%)$ \\
\hline Lasca angular & 25 & 3 & 3 & 0 & 0 & $31(57,40 \%)$ \\
\hline Lasca con dorso natural & 2 & 0 & 0 & 0 & 0 & $2(3,70 \%)$ \\
\hline Lasca indiferenciada & 2 & 1 & 1 & 0 & 0 & $4(7,40 \%)$ \\
\hline Lasca plana & 2 & 0 & 0 & 0 & 0 & $2(3,70 \%)$ \\
\hline Lasca primaria & 3 & 1 & 0 & 0 & 0 & $4(7,40 \%)$ \\
\hline Lasca secundaria & 4 & 0 & 0 & 0 & 1 & $5(9,25 \%)$ \\
\hline TOTAL y \% & $42(76,36 \%)$ & $5(9,25 \%)$ & $4(7,40 \%)$ & $1(1,85 \%)$ & $2(3,70 \%)$ & 54 \\
\hline
\end{tabular}

por ejemplo, un núcleo de obsidiana negra (Tabla 10). Cabe señalar que fuera del muestreo se registró un pequeño guijarro de obsidiana negra.

En las Tablas 11 y 12 puede verse que continúa la tendencia respecto del desarrollo de las primeras etapas de la manufactura de artefactos.

\section{CABEZA DE LEÓN (C DE LEÓN)}

Se registraron 39 artefactos formatizados y 303 desechos de talla. Las litologías presentes son muy variadas; entre ellas, se destacan la obsidiana negra y verde. La diversidad de clases artefactuales y de desechos de talla es amplia, destacándose la reserva de corteza (lascas primarias y secundarias). La lectura de la Tabla 13 indica que las clases artefactuales se polarizan entre núcleos y raederas por un lado y el resto de las clases por el otro. Hay nuevas clases artefactuales respecto de los otros conjuntos, aunque en muy baja frecuencia: bola, percutor y molino. Fuera de las cuadrículas, sobre el camino, se recuperaron dos yunques, uno de los cuales presenta evidencias de haber sido utilizado también como percutor.

Es de destacar la alta frecuencia de núcleos y la ausencia de desechos que los acompañen, como en el caso de la lutita. Es importante, asimismo, la alta frecuencia de rocas que presentan solamente desechos de talla (6/14) (Tabla 14). Este sesgo probablemente sea el resultado de recolecciones asistemáticas por parte de coleccionistas. Las Tablas 14 y 15 muestran el desarrollo de actividades de manufactura lítica en una gran diversidad de rocas; sustentado en las variedades de desechos asociados a estas tareas (Tabla 13): preparación de núcleos y tecnología bifacial. La presencia de corteza (Tabla 15) es significativa entre los desechos de talla de riolita y señala el desarrollo de desbaste inicial. No obstante, la diversidad de clases artefactuales y de desechos de talla reflejan mayor variedad de actividades y de

Tabla 11. SIT 7, Porcentajes de artefactos formatizados y desechos de talla por materia prima.

\begin{tabular}{|c|c|c|c|c|c|}
\cline { 2 - 6 } \multicolumn{1}{c|}{} & \multicolumn{5}{c|}{ MATERIA PRIMA } \\
\cline { 2 - 6 } \multicolumn{1}{c|}{} & Dacita & Basalto & Calcedonia & Obsidiana negra & $\begin{array}{c}\text { Madera } \\
\text { silicificada }\end{array}$ \\
\hline Artefactos formatizados & 7,14 & 0 & 0 & 100 & 50 \\
\hline Desechos de talla & 92,85 & 100 & 100 & 0 & 50 \\
\hline
\end{tabular}

Tabla 12. SIT 7, Porcentajes de desechos de talla corticales e internos por materia prima.

\begin{tabular}{|c|c|c|c|c|}
\cline { 2 - 5 } \multicolumn{1}{c|}{} & \multicolumn{4}{c|}{ MATERIA PRIMA } \\
\cline { 2 - 5 } \multicolumn{1}{c|}{} & Dacita & Basalto & Calcedonia & Madera silicificada \\
\hline Desechos de talla corticales & 23,07 & 20 & 0 & 100 \\
\hline Desechos de talla internos & 76,92 & 80 & 100 & 0 \\
\hline
\end{tabular}




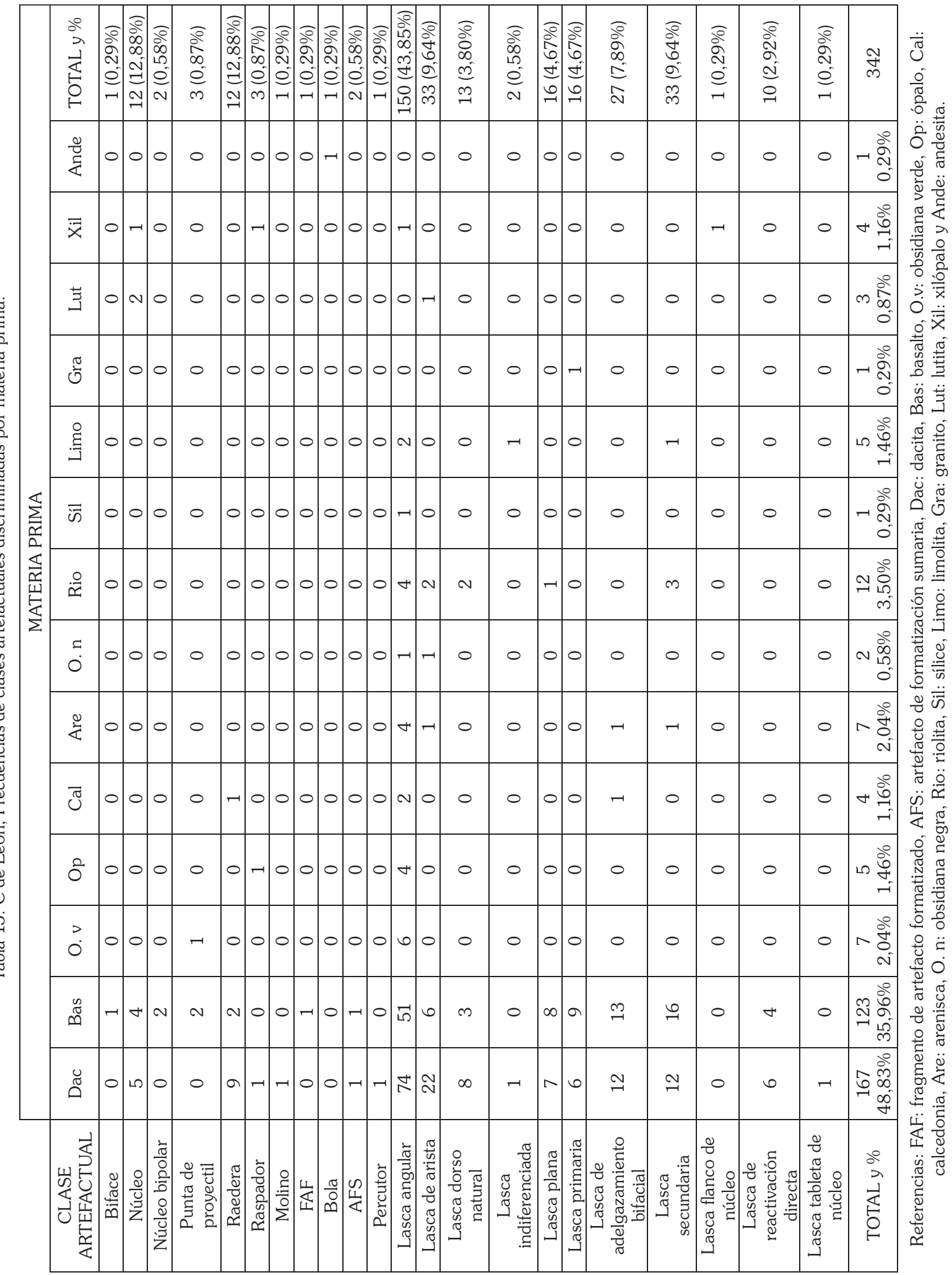


Tabla 14. C de León, Porcentajes de artefactos formatizados y desechos de talla por materia prima.

\begin{tabular}{|c|c|c|c|c|c|c|c|c|c|c|c|c|c|c|}
\hline & \multicolumn{14}{|c|}{ MATERIA PRIMA } \\
\hline & Dac & Bas & O.v & $\mathrm{Op}$ & Cal & Are & O.n & Rio & Síl & Limo & Luti & Gra & Xil & Ande \\
\hline $\begin{array}{c}\text { Artefactos } \\
\text { formatizados }\end{array}$ & 10,17 & 10,56 & 14,28 & 25 & 20 & 0 & 0 & 0 & 0 & 0 & 66,6 & 0 & 50 & 100 \\
\hline $\begin{array}{c}\text { Desechos de } \\
\text { talla }\end{array}$ & 89,82 & 89,43 & 85,72 & 75 & 80 & 100 & 100 & 100 & 100 & 100 & 33,3 & 100 & 50 & 0 \\
\hline
\end{tabular}

Referencias: Dac: dacita, Bas: basalto, O.v: obsidiana verde, Op: ópalo, Cal: calcedonia, Are: arenisca, O. n: obsidiana negra,

Rio: riolita, Sil: sílice, Limo: limolita, Luti: lutita, Gra: granito, Xil: xilópalo y Ande: andesita.

Tabla 15. C de León, Porcentajes de desechos de talla corticales e internos por materia prima.

\begin{tabular}{|c|c|c|c|c|c|c|c|c|c|c|c|c|}
\hline & \multicolumn{12}{|c|}{ MATERIAS PRIMAS } \\
\hline & Basalto & Dacita & $\begin{array}{c}\text { Obsidiana } \\
\text { verde }\end{array}$ & Ópalo & Calcedonia & Arenisca & $\begin{array}{c}\text { Obsidiana } \\
\text { negra }\end{array}$ & Riolita & Sílice & Limolita & Lutita & Granito \\
\hline $\begin{array}{l}\text { Desechos de } \\
\text { talla corticales }\end{array}$ & 25,4 & 17,4 & 0 & 0 & 0 & 14,2 & 0 & 41,6 & 0 & 20 & 0 & 100 \\
\hline $\begin{array}{l}\text { Desechos de } \\
\text { talla internos }\end{array}$ & 74,5 & 82,5 & 100 & 100 & 100 & 85,7 & 100 & 58,3 & 100 & 80 & 100 & 0 \\
\hline
\end{tabular}

Tabla 16. SPS, Frecuencias de clases artefactuales por materia prima.

\begin{tabular}{|c|c|c|c|c|}
\cline { 2 - 4 } \multicolumn{2}{c|}{} & \multicolumn{4}{c|}{ MATERIAS PRIMAS } \\
\hline CLASES ARTEFACTUALES & Dacita & Basalto & Calcedonia & TOTAL y $\%$ \\
\hline Biface & 1 & 0 & 0 & $1(0,61 \%)$ \\
\hline Cepillo & 1 & 0 & 0 & $1(0,61 \%)$ \\
\hline Cuchillo & 2 & 0 & 0 & $1(1,22 \%)$ \\
\hline FAF & 1 & 0 & 0 & $4(2,45 \%)$ \\
\hline Muesca & 3 & 1 & 0 & $19(11,65 \%)$ \\
\hline Núcleo & 17 & 2 & 0 & $1(0,61 \%)$ \\
\hline Núcleo + percutor & 1 & 0 & 0 & $12(7,36 \%)$ \\
\hline Raedera & 9 & 3 & 0 & $2(1,22 \%)$ \\
\hline Raspador & 2 & 0 & 1 & $54(33,12 \%)$ \\
\hline Lasca angular & 42 & 12 & 1 & $5(3,06 \%)$ \\
\hline Lasca de arista & 4 & 0 & 0 & $5(3,06 \%)$ \\
\hline Lasca de adelgazamiento bifacial & 3 & 1 & 0 & $20(12,26 \%)$ \\
\hline Lasca dorso natural & 17 & 3 & 0 & $1(0,61 \%)$ \\
\hline Lasca flanco de núcleo & 1 & 0 & 0 & $5(3,06 \%)$ \\
\hline Lasca plana & 5 & 0 & 0 & $12(12,26 \%)$ \\
\hline Lasca primaria & 8 & 4 & 0 & $6(3,68 \%)$ \\
\hline Lasca reducción directa & 5 & 1 & 27 & $11(6,74 \%)$ \\
\hline Lasca secundaria & 11 & $(16,56 \%)$ & $(1,84 \%)$ & 163 \\
\hline TOTAL y $\%$ & $(81,59 \%)$ & & & 0 \\
\hline
\end{tabular}

Tabla 17. SPS, Porcentajes de artefactos formatizados y desechos de talla por materias primas.

\begin{tabular}{|c|c|c|c|}
\cline { 2 - 4 } \multicolumn{1}{c|}{} & \multicolumn{3}{c|}{ MATERIA PRIMA } \\
\cline { 2 - 4 } \multicolumn{1}{c|}{} & Dacita & Basalto & Calcedonia \\
\hline Artefactos formatizados & 27,8 & 22,2 & 0 \\
\hline Desechos de talla & 72,18 & 77,7 & 100 \\
\hline
\end{tabular}

Tabla 18. SPS, Porcentajes de desechos de talla corticales e internos por materia prima.

\begin{tabular}{|c|c|c|c|}
\cline { 2 - 4 } \multicolumn{1}{c|}{} & \multicolumn{3}{c|}{ MATERIA PRIMA } \\
\cline { 2 - 4 } \multicolumn{1}{c|}{} & Dacita & Basalto & Calcedonia \\
\hline Desechos de talla corticales & 52,17 & 25,92 & 0 \\
\hline Desechos de talla internos & 47,82 & 74,07 & 100 \\
\hline
\end{tabular}


etapas de manufactura que en otros conjuntos. Cabe destacar la punta de proyectil de obsidiana verde y los desechos que la acompañan (ver adelante) por tratarse de una roca alóctona.

\section{SECTOR PINGUINERA SUR (SPS)}

El total de piezas registrado en la transecta asciende a 196: 43 artefactos formatizados y 120 desechos de talla. Siete son las clases artefactuales, sin embargo, las materias primas son sólo tres y concordantes con las más representadas en toda el área relevada (Tabla 16).

En la Tabla 17 se observa que los artefactos formatizados alcanzan valores mayores que en otros conjuntos, pudiendo interpretarse como el desarrollo de una diversa gama de actividades. Sin embargo, son los núcleos los más representados. De modo que, nuevamente, las primeras etapas de manufactura son las tareas mejor evidenciadas (Tabla 18).

\section{CONSIDERACIONES GENERALES}

Del análisis comparativo de los conjuntos analizados, se desprende que en los casos de bajas frecuencias artefactuales (SIT 6, SIT 7 y CCH 4) hay menor variabilidad de materias primas y de clases artefactuales presentes. En contrapartida a esta tendencia se incrementa el porcentaje de lascas internas. Un comportamiento diferente se pone en evidencia en los sitios con mayor frecuencia artefactual (CONC10, C de León) y -aunque en menor proporción- la transecta SPS. En ellos es mayor la variedad de tipos de rocas representados y de clases artefactuales.

Más allá de los problemas de muestra recién señalados, las tendencias indican el uso generalizado de materias primas locales; principalmente, dacita en sus variedades verde y gris y de diversas calidades para la talla, seguida por basalto, calcedonia y, en menores proporciones, lutita, ópalo, limolita, arenisca, riolita, sílice, diabasa y granito. Aunque en porcentajes bajos, se han recuperado artefactos manufacturados en rocas alóctonas, como en tres de las variedades de obsidiana registradas en Patagonia austral: negra, verde y gris verdosa veteada. La primera de ellas provendría de la Pampa del Asador (Espinosa y Goñi 1999; Stern 1999), situada a $320 \mathrm{~km}$ hacia el NO; la segunda del Mar de Otway,

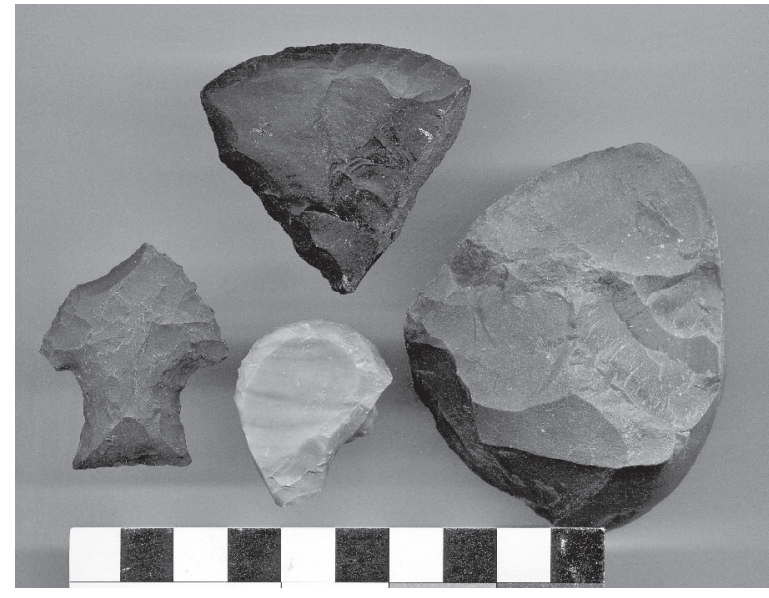

Fig. 3. Algunos de los artefactos líticos recuperados en el Parque Nacional Monte León.

en Magallanes, Chile (Morello et al. 2001, 2004), localizado $340 \mathrm{~km}$ hacia el SO y la última de ellas de la cordillera Baguales (Stern y Franco 2000), a $240 \mathrm{~km}$ al O. Esto mostraría la inclusión de Monte León dentro de circuitos mayores de circulación de rocas. Por otra parte, se observó alteración térmica sobre algunos desechos de talla de calcedonia.

Las únicas clases artefactuales que se distribuyen de manera homogénea a lo largo de todo el espacio son lascas, núcleos y raederas (superan el $80 \%$ del conjunto de cada sitio). Los notorios porcentajes de corteza en los desechos de talla destacan el desarrollo de las primeras etapas de la manufactura en todos los sectores analizados. Esto se relacionaría con una alta disponibilidad local de materias primas de calidad adecuada para la talla (dacita, basalto, calcedonia-observadas principalmente en SIT 7). Dicho aprovisionamiento se ve reflejado también en la presencia de corteza en desechos de talla de dacita y basalto y en el registro de núcleos en todos los conjuntos de superficie. Si bien los desechos internos superan a los corticales en todos los conjuntos, SPS se presenta como un caso particular, en el que los últimos alcanzan el 52,17\% en dacita. En términos generales se ve una gran homogeneidad en el tipo de actividades realizadas en los distintos sitios (ver Fig. 3).

Por otra parte, la buena conservación de los materiales -bajo índice de fracturas, ausencia de pátinas y rodamiento- está indicando la reciente exposición del mismo por pérdida de la matriz sedimentaria (ver Caracotche 2003). 
Tabla 19. Total de restos de vertebrados recuperados en el P. N. Monte León.

\begin{tabular}{|c|c|c|c|c|c|}
\cline { 2 - 6 } \multicolumn{1}{c|}{} & \multicolumn{3}{c|}{ CCH 4 } & \multicolumn{2}{c|}{ SIT 6 } \\
\cline { 2 - 6 } \multicolumn{1}{c|}{} & Astillas & NISP & MNE & NISP & MNE \\
\hline Excavación & 40 & 75 & 51 & 4 & 2 \\
\hline Recolecciones & 9 & 131 & 106 & - & - \\
\hline Total & 49 & 206 & 157 & 4 & 2 \\
\hline
\end{tabular}

En cuanto a la manufactura de los artefactos, se observan distintas calidades en la inversión de energía; los filos formatizados cuentan con una o dos series de lascados marginales y ultramarginales, presentándose en algunos casos sobre lascas con reserva de corteza (primarias, secundarias). Por el contrario, la manufactura de piezas bifaciales implica una alta inversión de energía. La presencia de tecnología bifacial se observó en todos los conjuntos a excepción de $\mathrm{CCH} 4$, a través de puntas de proyectil o de bifaces y de lascas de adelgazamiento bifacial. Asimismo, es posible evidenciar la cadena completa de producción: diferentes tamaños de lascas de adelgazamiento bifacial y bifaces en distintos estadios de manufactura.

\section{LOS RESTOS DE FAUNA}

Se recuperaron restos de vertebrados en CCH 4 y SIT 6. En la Tabla 19 se presentan los valores de NISP y MNE para los conjuntos faunísticos de ambos sitios. La muestra de SIT 6 es muy pequeña, ya que consta de un único espécimen que pudo ser determinado taxonómicamente y tres fragmentos pequeños, que no pudieron asignarse a ningún elemento anatómico particular. El espécimen identificado es un tarsometatarso fragmentado de Spheniscidae, mientras que los tres fragmentos fueron determinados como correspondientes a mamíferos marinos.

En $\mathrm{CCH} 4$ se recuperó un total de 255 especímenes óseos, entre los provenientes de la excavación y recolecciones. Cuarenta y nueve de estos especímenes son fragmentos o astillas indeterminados a nivel anatómico, que además fueron asignados a categorías taxonómicas muy amplias.
Estos fragmentos no fueron considerados en el análisis general de las propiedades de este conjunto arqueofaunístico. Del total de restos identificados, 49 especímenes fueron determinados como pertenecientes a aves, 155 a mamíferos y 2 a peces. En la Tabla 19 se presentan los valores de NISP y MNE de aquellos especímenes que pudieron ser determinados anatómicamente y que constituyen la base del análisis que se presenta a continuación.

En la Tabla 20 se detalla la representación taxonómica registrada entre los huesos de aves. En SIT 6 sólo se determinó un espécimen correspondiente a Spheniscidae. En cambio, en $\mathrm{CCH} 4$ hay mayor cantidad de restos de aves y una mayor diversidad representada. Los restos de Spheniscidae de este conchero fueron recuperados durante la recolección efectuada en el perfil, en el sector cercano a dos nidos activos de pingüino de Magallanes (Spheniscus magellanicus). Por lo tanto, es muy posible que los mismos sean el resultado de la superposición de restos de pingüinos actuales con los materiales arqueológicos (Cruz 1999, 2004). Tres de los especímenes de ave de $\mathrm{CCH} 4$ pudieron ser determinados a nivel de género, todos ellos correspondientes a Phalacrocorax sp., mientras que un espécimen del mismo conchero fue determinado como de Rheidae.

En la Tabla 21 se puede observar la representación taxonómica registrada entre los restos de mamíferos. En SIT 6, los pequeños fragmentos recuperados fueron asignados a la categoría Mamíferos Indeterminados. En CCH 4 se determinaron restos pertenecientes a pinnípedos, cetáceos, guanaco (Lama guanicoe), roedores e indeterminados.

Entre los huesos de pinnípedos, seis pudieron ser determinados a nivel de especie. Los mismos

Tabla 20. Representación taxonómica (NISP) de los huesos de aves recuperados en el P. N. Monte León.

\begin{tabular}{|c|c|c|c|c|c|}
\hline $\begin{array}{c}\text { Categoría } \\
\text { taxonómica }\end{array}$ & Rheidae & Spheniscidae & Phalacrocoracidae & $\begin{array}{c}\text { Aves } \\
\text { indeterminadas }\end{array}$ & Total \\
\hline CCH 4 & 1 & 18 & 3 & 27 & 49 \\
\hline SIT 6 & - & 1 & - & - & 1 \\
\hline Total & 1 & 19 & 3 & 27 & 50 \\
\hline
\end{tabular}


Tabla 21. Representación taxonómica (NISP) de los huesos de mamíferos recuperados en el CCH 4 (P. N. Monte León).

\begin{tabular}{|c|c|c|c|c|c|c|}
\hline $\begin{array}{c}\text { Categoría } \\
\text { taxonómica }\end{array}$ & Pinnípedos & Cetáceos & Guanacos & Roedores & $\begin{array}{c}\text { Mamíferos } \\
\text { Indeterminados }\end{array}$ & Total \\
\hline CCH 4 & 115 & 2 & 18 & 7 & 13 & 155 \\
\hline SIT 6 & - & - & - & - & 3 & 3 \\
\hline Total & 115 & 2 & 18 & 7 & 16 & 158 \\
\hline
\end{tabular}

corresponden a Arctocephalus australis o lobo marino de dos pelos, especie actualmente ausente en la localidad. Estos especímenes son piezas dentarias y hemimandíbulas. Los restos de guanaco fueron marcadamente más escasos que los correspondientes a pinnípedos y, con excepción de un espécimen registrado en la excavación, provienen de recolecciones. En gran parte de los casos, estos especímenes son fragmentos de diferentes tamaños, especialmente de diáfisis de huesos largos.

En la Tabla 22 se presentan las modificaciones registradas en los huesos de aves. Todos los especímenes recuperados están desarticulados y porcentajes altos de cada muestra presentan fracturas. El perfil de meteorización de estos huesos (tanto de los correspondientes a la excavación, como los recuperados en recolecciones) está sesgado hacia los estadios más bajos (estadios 0,1 y 2). Sólo un porcentaje menor de los especímenes de $\mathrm{CCH} 4$ y el espécimen de SIT 6 están en estadio 3. Por otro lado, en dos de los especímenes (un tibiatarso y un fémur de Phalacrocorax sp.), recuperados en la excavación de $\mathrm{CCH} 4$, no pudo evaluarse la acción de la meteorización debido al estado de la capa externa de estos huesos.

Con respecto a las modificaciones asignables a carnívoros, las mismas sólo se registraron en el caso de un espécimen recuperado en la recolección del perfil del conchero, una falange de ñandú que presenta los daños denominados pitting y scoring, sumados a un borde crenulated (Binford 1981). Sólo uno de los especímenes de Spheniscidae, registrado en la recolección efectuada en el perfil, presenta modificaciones debidas a la acción del agua. Tres de los especímenes de Spheniscidae presentan marcas que se categorizaron como indeterminadas. Ninguno de los especímenes de ave presenta modificaciones asignables claramente a la actividad humana.

En las siguientes Tablas se presentan las modificaciones registradas en los restos de mamíferos. La Tabla 23 está dedicada a las observadas en los

Tabla 22. Modificaciones registradas en los huesos de aves recuperados en el P. N. Monte León.

\begin{tabular}{|c|c|c|c|c|}
\hline & & \multicolumn{2}{|c|}{$\mathrm{CCH} 4$} & \multirow{3}{*}{$\begin{array}{c}\text { SIT } 6 \\
100 \% \\
-\end{array}$} \\
\hline \multicolumn{2}{|c|}{ Variables } & Excavación & Recolecciones & \\
\hline $\begin{array}{c}\text { Grado de } \\
\text { articulación }\end{array}$ & $\begin{array}{c}\text { Desarticulados } \\
\text { Articulados }\end{array}$ & $\begin{array}{c}100 \% \\
- \\
\end{array}$ & $\begin{array}{c}100 \% \\
- \\
\end{array}$ & \\
\hline Meteorización & $\begin{array}{c}\text { No meteorizados } \\
\text { Estadio } 1 \\
\text { Estadio } 2 \\
\text { Estadio } 3 \\
\text { Indeterminado }\end{array}$ & $\begin{array}{c}33 \% \\
- \\
45 \% \\
- \\
22 \%\end{array}$ & $\begin{array}{c}50 \% \\
27,5 \% \\
17,5 \% \\
5 \% \\
-\end{array}$ & $\begin{array}{c}- \\
- \\
100 \% \\
- \\
-\end{array}$ \\
\hline Fracturas & $\begin{array}{c}\text { Fracturados } \\
\text { No fracturados }\end{array}$ & $\begin{array}{l}55 \% \\
35 \%\end{array}$ & $\begin{array}{l}60 \% \\
40 \%\end{array}$ & $\begin{array}{c}100 \% \\
-\end{array}$ \\
\hline $\begin{array}{l}\text { Modificaciones por } \\
\text { carnívoros }\end{array}$ & $\begin{array}{l}\text { Presencia } \\
\text { Ausencia }\end{array}$ & $100 \%$ & $\begin{array}{l}2,5 \% \\
97,5 \%\end{array}$ & $\begin{array}{c}- \\
100 \%\end{array}$ \\
\hline $\begin{array}{c}\text { Modificaciones } \\
\text { culturales }\end{array}$ & $\begin{array}{c}\text { Presencia } \\
\text { Ausencia }\end{array}$ & $100 \%$ & $\begin{array}{c}- \\
100 \%\end{array}$ & $\begin{array}{c}- \\
100 \%\end{array}$ \\
\hline $\begin{array}{l}\text { Modificaciones } \\
\text { indeterminadas }\end{array}$ & $\begin{array}{l}\text { Presencia } \\
\text { Ausencia }\end{array}$ & $\begin{array}{c}- \\
100 \%\end{array}$ & $\begin{array}{c}7,5 \% \\
92,5 \%\end{array}$ & $\begin{array}{c}- \\
100 \%\end{array}$ \\
\hline $\begin{array}{c}\text { Modificaciones por } \\
\text { agua }\end{array}$ & $\begin{array}{l}\text { Presencia } \\
\text { Ausencia }\end{array}$ & $100 \%$ & $\begin{array}{l}2,5 \% \\
97,5 \%\end{array}$ & $100 \%$ \\
\hline $\begin{array}{c}\text { Modificaciones por } \\
\text { raíces }\end{array}$ & $\begin{array}{l}\text { Presencia } \\
\text { Ausencia }\end{array}$ & $\begin{array}{c}- \\
100 \%\end{array}$ & $100 \%$ & $\begin{array}{c}- \\
100 \%\end{array}$ \\
\hline $\begin{array}{l}\text { Modificaciones } \\
\text { culturales }\end{array}$ & $\begin{array}{l}\text { Presencia } \\
\text { Ausencia }\end{array}$ & $100 \%$ & $100 \%$ & $100 \%$ \\
\hline
\end{tabular}


huesos de pinnípedos recuperados en $\mathrm{CCH} 4$. De estos especímenes, 46 fueron recuperados en la excavación, mientras que los 69 restantes corresponden a las recolecciones (del perfil y superficial). Como en el caso de los restos de aves, todos los huesos de pinnípedos están desarticulados. Además, tanto entre los especímenes de excavación como en los provenientes de recolecciones predominan los que presentan fracturas. Con respecto a la meteorización, el perfil determinado para los especímenes de la excavación difiere del establecido para los provenientes de las recolecciones: entre los restos de la excavación predominan aquellos que no muestran indicios de meteorización, en los recuperados en las recolecciones hay mayor representación de los levemente meteorizados (estadios 1 y 2 ) y meteorizados (estadios 3 y 4).

En dos de los especímenes (3\%) recuperados en las recolecciones se registraron modificaciones asignables a carnívoros. Las modificaciones indeterminadas se registraron en el 17\% de los especímenes, mientras que el 3\% de los mismos presenta la superficie quemada. Por otro lado, el 9\% presenta algún tipo de modificación cultural: cinco casos con huellas de corte y un húmero con marcado perimetral, recuperado en la recolección superficial (Fig. 4). Hasta el momento, en Patagonia el marcado perimetral ha sido registrado en huesos largos de

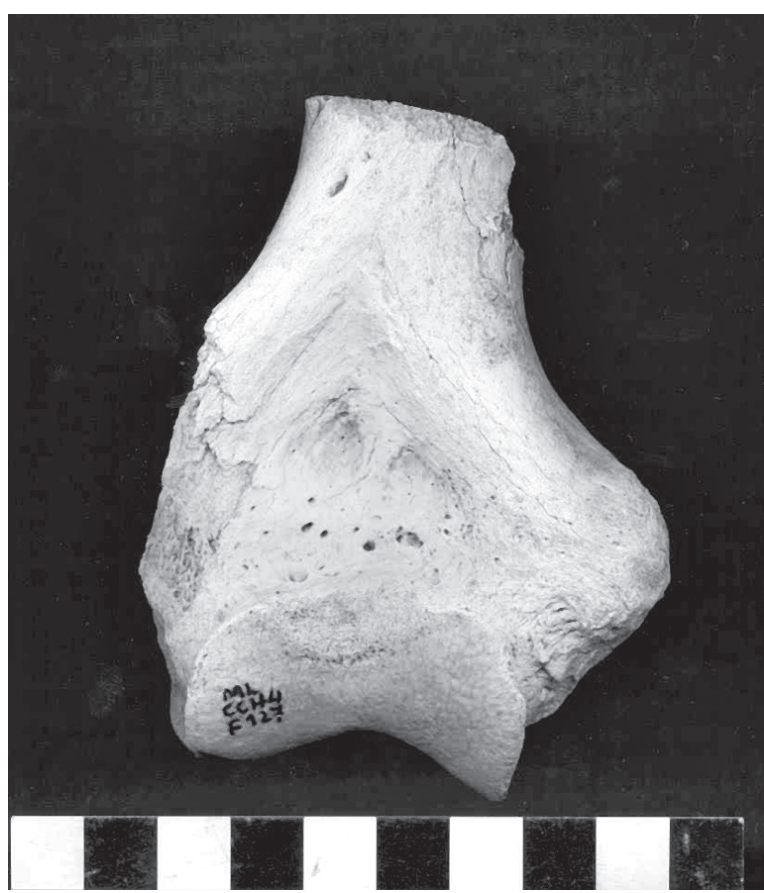

Fig. 4. Húmero de pinnípedo con marcado perimetral, recuperado en $\mathrm{CCH} 4$.

guanaco (Muñoz y Belardi 1998) y en huesos de ave (Cruz 2000), por lo que el espécimen de $\mathrm{CCH}$ 4 amplía el repertorio de los taxones sobre cuyos huesos se aplicó esta técnica.

Tabla 23. Modificaciones registradas en los huesos de pinnípedos recuperados en CCH 4 (P. N. Monte León).

\begin{tabular}{|c|c|c|c|}
\hline & & \multicolumn{2}{|c|}{$\mathrm{CCH} 4$} \\
\hline \multicolumn{2}{|c|}{ Variables } & Excavación & Recolecciones \\
\hline $\begin{array}{c}\text { Grado de } \\
\text { articulación }\end{array}$ & $\begin{array}{c}\text { Desarticulados } \\
\text { Articulados }\end{array}$ & $\begin{array}{c}100 \% \\
-\end{array}$ & $\begin{array}{c}100 \% \\
-\end{array}$ \\
\hline Meteorización & $\begin{array}{c}\text { No meteorizados } \\
\text { Estadio } 1 \\
\text { Estadio } 2 \\
\text { Estadio } 3 \\
\text { Estadio } 4 \\
\text { Indeterminado } \\
\text { No corresponde }\end{array}$ & $\begin{array}{c}70,5 \% \\
6,5 \% \\
13 \% \\
6,5 \% \\
- \\
- \\
4 \%\end{array}$ & $\begin{array}{c}20 \% \\
22,5 \% \\
23 \% \\
26 \% \\
1 \% \\
1 \% \\
6,5 \%\end{array}$ \\
\hline Fracturas & $\begin{array}{c}\text { Fracturados } \\
\text { No fracturados }\end{array}$ & $\begin{array}{l}67 \% \\
33 \%\end{array}$ & $\begin{array}{l}69,5 \% \\
30,5 \%\end{array}$ \\
\hline Modificaciones por carnívoros & $\begin{array}{l}\text { Presencia } \\
\text { Ausencia }\end{array}$ & $100 \%$ & $\begin{array}{l}3 \% \\
97 \%\end{array}$ \\
\hline Modificaciones indeterminadas & $\begin{array}{l}\text { Presencia } \\
\text { Ausencia }\end{array}$ & $\begin{array}{l}13 \% \\
83 \%\end{array}$ & $\begin{array}{l}17 \% \\
83 \%\end{array}$ \\
\hline Modificaciones por agua & $\begin{array}{l}\text { Presencia } \\
\text { Ausencia }\end{array}$ & $\begin{array}{c}- \\
100 \%\end{array}$ & $\begin{array}{c}- \\
100 \%\end{array}$ \\
\hline Quemado & $\begin{array}{l}\text { Presencia } \\
\text { Ausencia }\end{array}$ & $\begin{array}{c}- \\
100 \%\end{array}$ & $\begin{array}{c}3 \% \\
97 \%\end{array}$ \\
\hline Modificaciones culturales & $\begin{array}{l}\text { Presencia } \\
\text { Ausencia }\end{array}$ & $\begin{array}{l}6,5 \% \\
89 \%\end{array}$ & $\begin{array}{c}9 \% \\
91 \%\end{array}$ \\
\hline
\end{tabular}


Tabla 24. Modificaciones registradas en los huesos de guanaco recuperados en CCH 4 (P. N. Monte León).

\begin{tabular}{|c|c|c|c|}
\hline & & \multicolumn{2}{|c|}{$\mathrm{CCH} 4$} \\
\hline \multicolumn{2}{|c|}{ Variables } & Excavación & Recolecciones \\
\hline $\begin{array}{c}\text { Grado de } \\
\text { articulación }\end{array}$ & $\begin{array}{c}\text { Desarticulados } \\
\text { Articulados }\end{array}$ & $\begin{array}{c}100 \% \\
-\end{array}$ & $\begin{array}{c}100 \% \\
-\end{array}$ \\
\hline Meteorización & $\begin{array}{c}\text { No meteorizados } \\
\text { Estadio } 1 \\
\text { Estadio } 2 \\
\text { Estadio } 3\end{array}$ & $\begin{array}{c}- \\
- \\
- \\
100 \%\end{array}$ & $\begin{array}{c}6 \% \\
41 \% \\
18 \% \\
35 \%\end{array}$ \\
\hline Fracturas & $\begin{array}{c}\text { Fracturados } \\
\text { No fracturados }\end{array}$ & $\begin{array}{c}100 \% \\
-\end{array}$ & $\begin{array}{l}88 \% \\
12 \%\end{array}$ \\
\hline Modificaciones por carnívoros & $\begin{array}{l}\text { Presencia } \\
\text { Ausencia }\end{array}$ & $100 \%$ & $100 \%$ \\
\hline Modificaciones indeterminadas & $\begin{array}{l}\text { Presencia } \\
\text { Ausencia }\end{array}$ & $100 \%$ & $\begin{array}{l}35 \% \\
65 \%\end{array}$ \\
\hline Modificaciones por agua & $\begin{array}{c}\text { Presencia } \\
\text { Ausencia }\end{array}$ & $100 \%$ & $\begin{array}{c}6 \% \\
94 \% \\
\end{array}$ \\
\hline Quemado & $\begin{array}{l}\text { Presencia } \\
\text { Ausencia }\end{array}$ & $\begin{array}{c}- \\
100 \%\end{array}$ & $\begin{array}{c}- \\
100 \%\end{array}$ \\
\hline Marcas de raíces & $\begin{array}{c}\text { Presencia } \\
\text { Ausencia }\end{array}$ & $100 \%$ & $\begin{array}{c}6 \% \\
94 \% \\
\end{array}$ \\
\hline Modificaciones culturales & $\begin{array}{c}\text { Presencia } \\
\text { Ausencia }\end{array}$ & $100 \%$ & $\begin{array}{l}12 \% \\
88 \% \\
\end{array}$ \\
\hline
\end{tabular}

En la Tabla 24 se presentan las modificaciones registradas en los huesos de guanaco de $\mathrm{CCH} 4$. Como se dijo, se recuperó un único espécimen en la excavación y los restantes a través de las recolecciones efectuadas en el conchero. Todos ellos se recuperaron desarticulados y, como se especificó anteriormente, la mayoría son fragmentos de diáfisis de huesos largos -es decir que presentan un alto porcentaje de fracturas-. El perfil de meteorización muestra el predominio de huesos levemente meteorizados (estadios 1 y 2 ) y meteorizados (estadio 3 ). Debido a que casi la totalidad de estos restos fue recuperada en el perfil, es posible que las diferencias en la meteorización no se relacionen con diferentes tiempos de exposición antes de la cobertura por los sedimentos, sino que se deban a la acción de

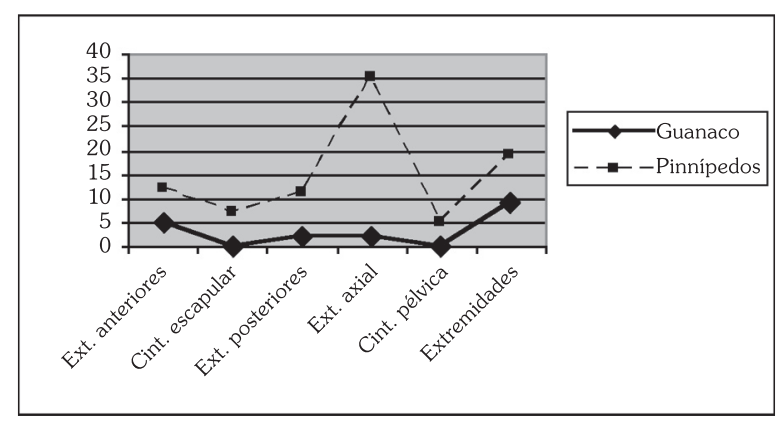

Fig. 5. Representación de partes esqueletarias (MNE) de Mamíferos en $\mathrm{CCH} 4$, P. N. Monte León. los procesos atmosféricos a medida que la erosión retrocedente, sumamente importante en este sector de la costa, exponía nuevamente los depósitos.

No se observaron modificaciones claramente atribuibles a la acción de carnívoros, pero un 35\% de los especímenes presentaba modificaciones indeterminadas. Se registraron escasas modificaciones debidas a la acción del agua y de las raíces. Entre los huesos de guanaco, dos presentan modificaciones culturales: un fragmento de diáfisis de hueso largo con huella de corte y la porción distal de un húmero con huellas de corte y marcado perimetral.

En la Fig. 5 se muestra la representación de partes esqueletarias de mamíferos (guanaco y pinnípedos) registrada en el conjunto arqueofaunístico analizado. El perfil de partes esqueletarias de guanaco muestra una mayor representación de las extremidades. Con excepción de dos vértebras, los especímenes asignados a este taxón corresponden a fragmentos de huesos largos, muchos de los cuales no pudieron ser asignados a un elemento específico. Puede verse que las extremidades anteriores son las más representadas, mientras que no se recuperaron restos correspondientes a la cintura pélvica y la escapular.

En cambio, en el caso de los pinnípedos hay una mayor diversidad de elementos representados, que corresponden a todas las unidades anatómicas definidas. Además, predominan los elementos 
del esqueleto axial, debido a la alta cantidad de costillas y vértebras. Están representadas ambas extremidades y también se registraron fragmentos de huesos largos indeterminados. Por su parte, aunque se recuperaron restos correspondientes a ambas cinturas articulares, la mejor representada es la escapular. En síntesis, los restos de pinnípedos son los que presentan una mayor diversidad de partes esqueletarias, lo cual con seguridad está relacionado con que la muestra correspondiente a este taxón es la más abundante, tanto en valores de NISP como de MNE.

En la Fig. 6 se presenta el perfil de partes esqueletarias de aves. Los restos de aves indeterminadas fueron fragmentos de vértebras y huesos correspondientes a las extremidades. Debido a la naturaleza fragmentada de estos restos, no se pudo avanzar en la asignación anatómica de los mismos, por lo que gran parte de los especímenes se incluyó en la categoría "extremidades". En el gráfico puede verse que entre los restos de cormoranes y de aves indeterminadas (mayoritariamente aves voladoras) predominaron los elementos correspondientes a las extremidades.

Por su parte, el perfil de partes esqueletarias registrado entre los restos de Spheniscidae coincide con el observado en depósitos naturales modernos (Cruz 1999, 2004). Es decir, los elementos más representados corresponden a ambas extremidades, con predominio de las posteriores. El único espécimen asignado a Rheidae corresponde a la porción inferior de las extremidades posteriores. Esto es concordante con la representación de elementos registrada en varios sitios arqueológicos de Patagonia y en conjuntos naturales (Belardi 1999; Cruz 2005), y puede ser un resultado de la atrición mediada por la densidad.

Un último aspecto que es necesario considerar es el grado de fusión de los elementos y la posibilidad de determinar clases de edad a partir del mismo. En la Tabla 25 se presentan los valores de NISP para

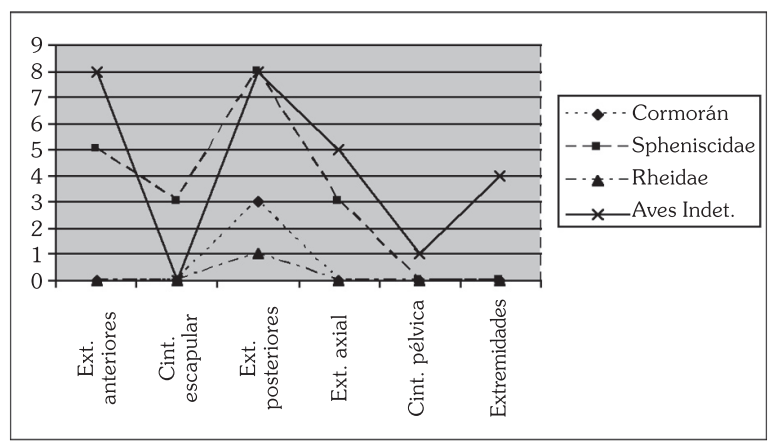

Fig. 6. Representación de partes esqueletarias (MNE) de Aves en $\mathrm{CCH} 4, \mathrm{P}$. N. Monte León.

los restos de Pinnípedos, aves indeterminadas, Spheniscidae y Phalacrocoracidae. En relación al grado de fusión detectado, se establecieron dos clases de edad: Adultos y Sub-adultos, para aquellos huesos fusionados y no fusionados, respectivamente. Los especímenes correspondientes a elementos en los que no corresponde la fusión (como piezas dentarias), se incluyeron en la categoría NC. Por otro lado, debido a que por la fragmentación de algunos elementos no estaban presentes las porciones diagnósticas de la fusión, los mismos se incluyeron en la categoría indeterminados.

Puede verse que entre los restos de pinnípedos predominan aquellos no fusionados. Debido a que entre éstos se incluyen cinco especímenes con modificaciones asignables a la actividad humana, es posible pensar que el aprovechamiento de estos animales fue efectuado durante primavera-verano, la estación de cría de los pinnípedos.

Entre los restos de aves, en cambio, no se han registrado especímenes con modificaciones culturales, por lo que no puede discutirse la interacción con los humanos a partir de los mismos. Sin embargo, la presencia de restos de individuos no maduros de pingüinos refuerza la idea de la contaminación de los depósitos arqueológicos con huesos actuales, derivados de los nidos emplazados en cercanía al conchero.

Tabla 25. Clases de edad representadas en los restos de $\mathrm{CCH} 4$ (P. N. Monte León). NC= no corresponde.

\begin{tabular}{|c|c|c|c|c|}
\cline { 2 - 5 } \multicolumn{1}{c|}{} & $\begin{array}{c}\text { Adultos } \\
\text { (Fusionados) }\end{array}$ & $\begin{array}{c}\text { Sub-adultos } \\
\text { (No Fusionados) }\end{array}$ & Indeterminados & NC \\
\hline Pinnípedos & 17 & 59 & 33 & 6 \\
\hline Aves indeterminadas & 4 & 8 & 15 & - \\
\hline Spheniscidae & 12 & 4 & 2 & 1 \\
\hline Phalacrocoracidae & 3 & - & - & - \\
\hline
\end{tabular}


En síntesis, las características del conjunto faunístico recuperado en $\mathrm{CCH} 4$ derivan de la acción conjunta de varios actores y procesos tafonómicos, entre los que se cuentan los cazadores humanos, los carnívoros y las aves nidificantes actuales, como los más importantes. La acción de los carnívoros fue claramente detectada en el 1,5\% de los especímenes de $\mathrm{CCH} 4$ (dos correspondientes a Pinnípedos y la falange de Rheidae), mientras que se registraron trazas de actividad humana en el 5\% de los especímenes (dos de guanaco y nueve asignados a pinnípedos). Debido a la falta de modificaciones de claro origen cultural y a la cercanía de nidos activos de pingüinos de Magallanes, los huesos de Spheniscidae asociados a los materiales arqueológicos de $\mathrm{CCH} 4$ constituyen otro caso de "contaminación" de depósitos arqueológicos por la incorporación de restos actuales de estas aves.

Por otro lado, los restos faunísticos recuperados reflejan la situación de deterioro en progreso detectada en los depósitos del sector. En efecto, algunas de las características tafonómicas que presentan los conjuntos analizados indican una mejor preservación de aquellos restos obtenidos a través de la excavación efectuada en el conchero $\mathrm{CCH}$ 4. Entre estas características, se destacan las diferencias entre los perfiles de meteorización de los restos de pinnípedos provenientes de la excavación y de la recolección efectuada en el perfil (ver Tabla 23).

\section{CONSIDERACIONES GENERALES ACERCA DEL REGISTRO ARQUEOLÓGICO DEL P. N. MONTE LEÓN}

Los resultados obtenidos en el marco del Proyecto de Rescate Arqueológico en el P. N. Monte León permiten una primera evaluación de las características del registro arqueológico y las ocupaciones humanas del Holoceno Medio y Tardío en la localidad. La evidencia recuperada ofrece un panorama general acerca del registro arqueológico de la costa de Monte León, que permitirá la puesta en valor de los diferentes sectores trabajados en el marco de este Proyecto. La información generada aporta a la discusión de diversos temas, como el poblamiento humano temprano de Patagonia, la historia de las interacciones entre poblaciones humanas y fauna $y$ el uso de la costa a lo largo del Holoceno. Los fecha- dos obtenidos indican un uso temprano del sector costero, lo cual coloca al registro arqueológico del P. N. Monte León en un lugar destacado dentro de la discusión acerca de la explotación de la costa en Patagonia continental. En efecto, los restos datados en 5150 años AP permiten plantear la utilización de recursos marinos -los moluscos- desde el Holoceno Medio en el sur de la costa continental. Esta evidencia se suma a la obtenida en cueva Las Buitreras (curso medio del río Gallegos), en donde se recuperaron restos arqueofaunísticos que indican el uso de la costa desde momentos tempranos (Borrero 2001; Gómez Otero et al. 1998). Como ya mencionamos, el otro fechado del Holoceno Medio para la costa de Santa Cruz es el obtenido en el sitio Cabo Tres Puntas (Castro y Moreno 1996-98).

La muestra faunística de Monte León indica el uso de diversos recursos costeros presentes actualmente en la costa patagónica, especialmente moluscos y mamíferos marinos. Uno de los aspectos particulares de Monte León es la explotación de una especie de pinnípedo -Arctocephalus australis- no presente actualmente en la localidad. Por otro lado, se registró una técnica de procesamiento de huesos -el marcado perimetral- sobre restos de pinnípedo, un taxón inédito hasta el momento en registros arqueológicos de Patagonia. Por último, la gran cantidad de restos de juveniles de pinnípedos está señalando la presencia humana y el aprovechamiento de estos animales durante primavera/verano. El uso de recursos marinos señalado por los restos de fauna presenta un marcado contraste con lo determinado a partir del análisis del material lítico. A pesar de la existencia en Patagonia continental de artefactos relacionados con la explotación de la fauna costera como arpones y rompecráneos (Gómez Otero 1995; Moreno et al. 2000), ninguno de los recuperados en Monte León evidencia una clara implementación de los mismos para la explotación de recursos marinos y costeros. En todo el conjunto artefactual hay una gran uniformidad tanto en lo que se refiere a la morfología, características tecnológicas y en las actividades que el mismo puede estar representando. Las materias primas líticas utilizadas permiten pensar en un aprovechamiento de los recursos locales e inmediatamente disponibles. No obstante, no se evidencia un uso intensivo de las rocas, ya que no se han registrado núcleos agotados y se observaron guijarros con pocas ex- 
tracciones. Estas características acercan a Monte León a las tendencias de los conjuntos líticos de la costa sur de Santa Cruz (Borrero y Franco 1999; Carballo Marina y Ercolano 2004). Por otra parte, los materiales líticos también están evidenciando el uso de materias primas no disponibles localmente, tal es el caso de las obsidianas negra, verde y gris verdosa veteada. Esta presencia de rocas alóctonas introduce a Monte León en el marco más amplio de la discusión acerca de la circulación supra-regional de materias primas.

Es necesario destacar que resulta inusual, para la costa continental del sur de Patagonia, la frecuencia y densidad de artefactos y de depósitos de valvas registrados en algunos de los sectores del Parque relevados en el marco de este Proyecto (Cabeza de León, Pingüinera Norte, Pingüinera Sur, Área de Acampe, Restinga Norte). En estos sectores, los materiales líticos se disponen en concentraciones muy densas y acotadas, lo que permite postular un uso recurrente de este espacio a lo largo de los últimos miles de años (ver también Castro et al. 2004).

Por último, se destaca que las características del registro arqueológico recuperado a través del Proyecto Rescate Arqueológico en Monte León son concordantes con las evaluaciones efectuadas por personal de la Administración de Parques Nacionales (2002; Caracotche 2003). Tal como se manifestara al presentar los resultados obtenidos, tanto las características que presentan los depósitos como las propiedades del registro arqueofaunístico y la gran visibilidad de los materiales líticos en el sector costero indican que el registro arqueológico del P. N. Monte León se encuentra en una situación de alta vulnerabilidad.

\section{AGRADECIMIENTOS}

Queremos agradecer a los Guardaparques Julia Delgado y Adrián Daros y a los brigadistas que también nos acompañaron durante las tareas en el campo. A la Dra. Florencia Borella (CONICETUNCPBA), por su colaboración en la determinación de los restos de mamíferos marinos, a Dra. Zulma Lizarralde y la Lic. Julieta Gómez Otero por la ayuda con los restos de invertebrados y a Cristina Raponi (DRP-APN) por su dedicación en la elaboración de la cartografía.

\section{BIBLIOGRAFÍA}

ADMINISTRACIÓN DE PARQUES NACIONALES. 2002. Plan de Manejo del futuro Parque Nacional Monte León. MS.

ASCHERO, C. 1975 (revisión 1983). Ensayo para una clasificación morfológica de artefactos líticos. Informe al CONICET. MS.

BEHRENSMEYER, A. K. 1978. Taphonomic and Ecological Information from Bone Weathering. Paleobiology 4:150-162.

BEHRENSMEYER, A. K. 1991. Terrestrial Vertebrate Accumulations. En: Taphonomy: Releasing the Data Locked in the Fossil Record. (Editado por P. A. Allison y D. E. G. Briggs). Plenum Press, New York, pp. 291-335.

BELARDI, J. B. 1999. Hay choiques en la Terraza. Información tafonómica y primeras implicaciones arqueofaunísticas para Patagonia. Arqueología 9: 163-185.

BINFORD, L. R. 1981. Bones. Ancient Men and Modern Myths. Academic Press, New York.

BORRERO, L. A. 2001. El poblamiento de la Patagonia. Toldos, milodones y volcanes. Emecé Editores, Buenos Aires.

BORRERO, L. A. y N. V. FRANCO. 1999. Arqueología de Cabo Vírgenes. Actas del XIII Congreso Nacional de Arqueología Argentina, Universidad Nacional de Córdoba, Córdoba, Argentina (En Prensa).

CARACOTCHE, M. S. 2003. La Arqueología de Monte León: Informe de situación. Delegación Regional Patagonia. Administración de Parques Nacionales. MS.

CARBALLO MARINA, F. y B. ERCOLANO. 2004. Una perspectiva geoarqueológica del uso humano de las marismas del río Gallegos durante el Holoceno. II Jornadas Patagónicas de Mallines y Humedales, Universidad Nacional de la Patagonia Austral, Río Gallegos, Santa Cruz, Argentina (CD ROM).

CASTRO, A.; J. E. MORENO; K. MARTINELLI, F. PEPE; V. DÍAZ y M. ZUBIMENDI. 1999. Los asentamientos indígenas tardíos en la costa norte de Santa Cruz y su relación con los recursos marinos. Actas del XIII Congreso Nacional de Arqueología Argentina, Córdoba (En Prensa).

CASTRO, A.; J. E. MORENO; K. MARTINELLI y F. PEPE. 2000. Restos faunísticos, artefactos líticos: más información sobre la costa norte de Santa Cruz. Desde el país de los gigantes. Perspectivas arqueológicas en Patagonia. Universidad Nacional de la Patagonia Austral, Río Gallegos, Tomo II:551-561.

CASTRO, A.; J. E. MORENO; M. ANDOLFO; R. GIMÉNEZ; C. PEÑA; L. MAZZITELLI y P. AMBRÚSTOLO. 2003. Análisis distribucionales en la costa de Santa Cruz (Patagonia argentina): alcances y resultados. Magallania 31:69-94

CASTRO, A.; J. GÓMEZ OTERO; G. ARRIGONI y J. E. MORENO. 2004. Prospección macrorregional comparativa a las Loberías de la costa de la Costa Atlántica Continental de Patagonia: algunas claves para el uso del espacio y de otros recursos. En: Contra viento y marea. Arqueología de la Patagonia. Editado por T. Civalero, P. Fernández y A.G. Guraieb. Instituto Nacional de Antropología y Pensamiento Latinoamericano, Buenos Aires, pp. 197-215. 
CRUZ, I. 1999. Pingüinos de Cabo Vírgenes (Santa Cruz). Aspectos tafonómicos e implicaciones arqueológicas. Resúmenes del XIII Congreso Nacional de Arqueología Argentina, pp. 389-391. Universidad Nacional de Córdoba, Argentina.

CRUZ, I. 2000. Los restos de aves de los sitios arqueológicos del Parque Nacional Perito Moreno (Santa Cruz, Argentina). Anales del Instituto de la Patagonia, Serie Cs. Sociales (Punta Arenas, Chile) 28: 305-313.

CRUZ, I. 2001. Los pingüinos como presas durante el Holoceno. Información biológica, fósil y arqueológica para evaluar su disponibilidad en el sur de Patagonia. Archaeofauna, International Journal of Archaeozoology 10:99-112.

CRUZ, I. 2003. Paisajes tafonómicos de restos de Aves en el sur de Patagonia continental. Aportes para la interpretación de conjuntos avifaunísticos en registros arqueológicos del Holoceno. Tesis Doctoral, Universidad de Buenos Aires, MS.

CRUZ, I. 2004. Tafonomía de huesos de Aves en Punta Medanosa (Dpto. Puerto Deseado, Santa Cruz). En: Contra viento y marea. Arqueología de la Patagonia. Editado por T. Civalero, P. Fernández y A.G. Guraieb. Instituto Nacional de Antropología y Pensamiento Latinoamericano, Buenos Aires, pp. 455-468.

CRUZ, I. 2005. La representación de partes esqueletarias de aves. Patrones naturales e interpretación arqueológica. Archaeofauna, International Journal of Archaeozoology 14 (En Prensa).

DEL VALLE, H. F.; N. O. ELISSALDE; D. A. GAGLIARDINI y J. MILOVICH. 1998. Status of Desertification in the Patagonian Region: Assessment and Maping from Satellite Imagery. Arid Soil Research and Rehabilitation 12:95-122.

ESPINOSA, S. y R. A. GOÑI. 1999. ¡Viven! Una fuente de obsidiana en la provincia de Santa Cruz. En: Soplando en el viento. Actas de las III Jornadas de Arqueología de la Patagonia. Universidad Nacional del Comahue, pp. 177-188.

GOMEZ OTERO, J.; J. L. LANATA y A. PRIETO. 1998. Arqueología de la Costa Atlántica Patagónica. Revista Americana de Arqueología 15:107-184.

GRADIN, C. J. 1963. Concheros y materiales líticos de Monte León (Pcia. de Santa Cruz). Acta Praehistórica VVII:53-71.

LEFÈVRE, C. 1989. L'avifaune de Patagonie australe et ses relations avec l'homme au cours des six dernieres millénaires. Tesis Doctoral de la Université PanthéonSorbonne, Paris. MS.

L'HEUREUX, G. L. y N. V. FRANCO. 2002. Ocupaciones humanas en el área de Cabo Vírgenes (Pcia. de Santa Cruz, Argentina): el sitio Cabo Vírgenes 6. Anales del Instituto de la Patagonia, Serie Ciencias Sociales 30:183-201.

LYMAN, R. L. 1994. Vertebrate Taphonomy. Cambridge University Press, Cambridge.

MANSUR, M.E., A. LASSA y M. VÁZQUEZ. 2004. Investigaciones arqueológicas en Punta Bustamante, Prov. de Santa Cruz: el sitio RUD01BK. En: Contra viento y marea. Arqueología de la Patagonia. Editado por M. T. Civalero; P. M. Fernández y A. G. Guraieb. Instituto
Nacional de Antropología y Pensamiento Latinoamericano - Sociedad Argentina de Antropología, Buenos Aires, pp. 755-774.

MANZI, L. 2004. La obsidiana verde como indicador del uso del espacio en Fuego-Patagonia. En: Contra viento y marea. Arqueología de la Patagonia. Editado por M. T. Civalero; P. M. Fernández y A. G. Guraieb. Instituto Nacional de Antropología y Pensamiento Latinoamericano - Sociedad Argentina de Antropología, Buenos Aires, pp: 117-134.

MORELLO, F.; M. SAN ROMÁN, A. PRIETO y C. STERN. 2001. Nuevos antecedentes para una discusión arqueológica en torno a la obsidiana verde en Patagonia Meridional. Anales del Instituto de la Patagonia, Serie Ciencias Sociales 29:129-148.

MORELLO, F.; M. SAN ROMÁN y A. PRIETO. 2004. Obsidiana verde en Fuego Patagonia: distribución y estrategias tecnológicas. En: Contra viento y marea. Arqueología de la Patagonia. Editado por M. T. Civalero; P. M. Fernández y A. G. Guraieb. Instituto Nacional de Antropología y Pensamiento Latinoamericano - Sociedad Argentina de Antropología, Buenos Aires., pp. 149-166.

MORENO, E. y A. CASTRO. 1995-1996. Costa norte de Santa Cruz como excepción al modelo de cazadores de guanaco. Anales de Arqueología y Etnología (F. F. y L. - U. N. de Cuyo) 50-51:13-22.

MORENO, J. E.; A. CASTRO y F. PEPE. 2000. El rompecráneo: un artefacto probablemente destinado para la caza de pinnípedos, en la costa de Patagonia continental. En: Desde el país de los gigantes. Perspectivas arqueológicas en Patagonia. Universidad Nacional de la Patagonia Austral, Río Gallegos, Tomo II:563-572.

MORENO, E.; A. CASTRO; K. MARTINELLI y A. ABELLO. 1998. El material faunístico de Cabo Blanco 1. Anales del Instituto de la Patagonia, Serie Ciencias Sociales 26:169-180.

MUÑOZ, A. S. y J. B. BELARDI. 1998. El marcado perimetral en los huesos largos de guanaco de Cañadón Leona (Colección Junius Bird): implicaciones arqueofaunísticas para Patagonia Meridional. Anales del Instituto de la Patagonia, Serie Ciencias Sociales 26: 107-117.

MUÑOZ, A. S. y F. SAVANTI. 1998. Observaciones tafonómicas sobre restos avifaunísticos de la costa noreste de Tierra del Fuego. Actas y Memorias del XI Congreso Nacional de Arqueología Argentina (8ํㅜ Parte), Revista del Museo de Historia Natural de San Rafael Tomo XX 1/2:107-121.

STERN, C. 1999. Black obsidian from central-south Patagonia: Chemical characteristics, sources and regional distribution of artifacts. En: Soplando en el viento. Actas de las III Jornadas de Arqueología de la Patagonia. INAPL-UNCOMA, pp. 221-235.

STERN, C. y N. V. FRANCO. 2000. Obsidiana gris verdosa veteada de la cuenca superior del río Santa Cruz, extremo sur de la Patagonia. Anales del Instituto de la Patagonia, Serie Ciencias Sociales 28:265-273.

STERN, C.; A. PRIETO y N. V. FRANCO. 1995. Obsidiana negra en sitios arqueológicos de cazadores recolectores terrestres en Patagonia Austral. Anales del Instituto de la Patagonia, Serie Ciencias Sociales 23:105-109. 
